\title{
SDRE Control Applied to the Wheel Speed of a Compressed Air Engine with Crank-Connecting-Rod Mechanism
}

\author{
Alexandre de Castro Alves, ${ }^{1,2}$ Angelo Marcelo Tusset, ${ }^{2}$ \\ Jose Manoel Balthazar, ${ }^{1,3}$ Jeferson Jose de Lima, ${ }^{1}$ Frederic Conrad Janzen, ${ }^{2}$ \\ Rodrigo Tumolin Rocha, ${ }^{2}$ and Airton Nabarrete ${ }^{3}$ \\ ${ }^{1}$ Sao Paulo State University, Bauru, SP, Brazil \\ ${ }^{2}$ Federal University of Technology-Parana, Ponta Grossa, PR, Brazil \\ ${ }^{3}$ Aeronautics Technological Institute, São José dos Campos, SP, Brazil \\ Correspondence should be addressed to Jose Manoel Balthazar; jmbaltha@ita.br
}

Received 6 March 2017; Revised 11 May 2017; Accepted 23 May 2017; Published 15 August 2017

Academic Editor: Mario Terzo

Copyright (C) 2017 Alexandre de Castro Alves et al. This is an open access article distributed under the Creative Commons Attribution License, which permits unrestricted use, distribution, and reproduction in any medium, provided the original work is properly cited.

\begin{abstract}
Renewable energy sources for vehicles have been the motivation of many researches around the world. The reduction of fossil fuels deposits and increase of the pollution in cities bring the need of more efficient and cleaner energy sources. In this way, this work will present the application of a compressed air engine applied to a bicycle. The engine is composed of two pneumatic cylinders connected to the bicycle wheel through a crank-connecting-rod mechanism. In order to control the velocity of the bicycle, a strategy of control composed of two controls was implemented: a feedback and a feedforward control. For feedback control, the StateDependent Riccati Equation (SDRE) control and also a proportional-derivative (PD) control are considered, considering three cases for velocity bicycle variation: $10 \mathrm{~km} / \mathrm{h}, 20 \mathrm{~km} / \mathrm{h}$, and $30 \mathrm{~km} / \mathrm{h}$. The equations of motion of the system were obtained through the Lagrangian energy method. Numerical simulations were performed in order to analyze the dynamics of the system and the efficiency of the controllers.
\end{abstract}

\section{Introduction}

The use of energy has become every time more intense through the society in the last decades; however, most of this energy comes from nonrenewable resources like oil, natural gas, and coils, that is, fossil fuels in general.

In order to convert these kinds of energy sources into energy of movement, especially in vehicles, the main mechanism of engines, which is responsible for this transformation is the crank-connecting-rod.

The crank-connecting-rod mechanism has been windily studied with the objective of increasing the engine performance. Some of these studies consider the movement in function of the system's geometry, noises, and vibrations induced by this mechanism [1-3].

Due to the limited current sources of fossil fuels, because of the world demand, and the need of improving vehicular performance, the study of new energy matrices like Hybrid Renewable Energy Systems (HRES) has been of great interest to numerous researchers $[4,5]$.

In this context, the compressed air systems become a very interesting alternative. The compressed air systems allow the energy recovery in the form of pressure, which can be applied as an extra energy source to the combustion engines, which characterizes a hybrid engine [6].

Pneumatic motors are very interesting in these applications because of their high force in relation to their masses [7]. In this way, many authors have been interested in the research of the application of compressed air engines in small vehicles, for example, motorcycles [8-10].

Therefore, this work proposes the application of a pneumatic motor to a bicycle as a main force generator. The pneumatic engine is composed of two pneumatic cylinders connected through a crank-connecting-rod mechanism to 
the bicycle wheel. Hence, the force generated by the compressed air is converted into angular movement of the wheel and into linear movement of the bicycle.

The crank-connecting-rod mechanism converts the linear force of the pneumatic cylinders into torque applied to the wheel considered as a single-degree-of-freedom system. In addition, the dynamic model is nonlinear because of the complexity of variables. Taking into account the fact that the velocity of the bicycle will be controlled, this work presents the application of the SDRE control and a PD control.

The SDRE control technique is a suboptimal control, which searches for local stabilities of a system [11]. The advantage of this control technique is that it does not cancel possible benefits provided by nonlinearities of the system, due to the fact that it is not necessary to linearize the system when applying this technique [12-16]. Among successful techniques implemented in real applications, there is the classical proportional-derivative (PD) controllers [17-19].

The next sections will show the mathematical modelling of the system composed of the wheel and the pneumatic engine composed of the crank-connecting-rod and the pneumatic cylinders. The SDRE and PD controllers will be presented and numerical simulations will be performed in order to analyze the system dynamics.

The remainder of this paper is organized as follows. Section 2 presents the literature related to the engineering problem and its mathematical modelling through subsections with the equations of motion and the control designs for SDRE and PD. In Section 3 the parameters and numerical results of the simulations with the results of applied controls SDRE and PD are presented with the discussions of the errors. Section 4 presents the final conclusions for the study presented in this article. In addition, posttextual elements that make up the structure of the work are described. Acknowledgments and references for literature are presented in sequence. Finally, the technical terms are presented through a glossary section with a large volume of presented terms.

\section{The Engineering Problem Design and Mathematical Modelling}

By applying compressed air force $\left(F_{\mathrm{a}}\right)$ to the crankconnecting-rod mechanism, it changes the position of the connecting-rod and generates the angular displacement of the crank. It is considered that the links of the system have their mass distribution proportional to a mass concentered in the Center of Gravity (CG) of each link.

Figure 1 presents a schematic draw of the crankconnecting-rod mechanism. This mechanism has restrictions to move in the vertical direction because of the cylinder but can translate free in $x$ direction. This vertical displacement restriction enables the system to move in relation to its length $\left(s_{\mathrm{CGcy}}\right)$, which generates the angular movement because of its connection to the connecting-rod.

These mechanisms presented in Figure 1 are a singledegree-of-freedom system with the displacement of the pneumatic cylinder varying the Top Dead Center (TDC) up to the Bottom Dead Center (BDC), thus rotating the output crank in $2 \pi \mathrm{rad}$. The linear position of the cylinder in relation

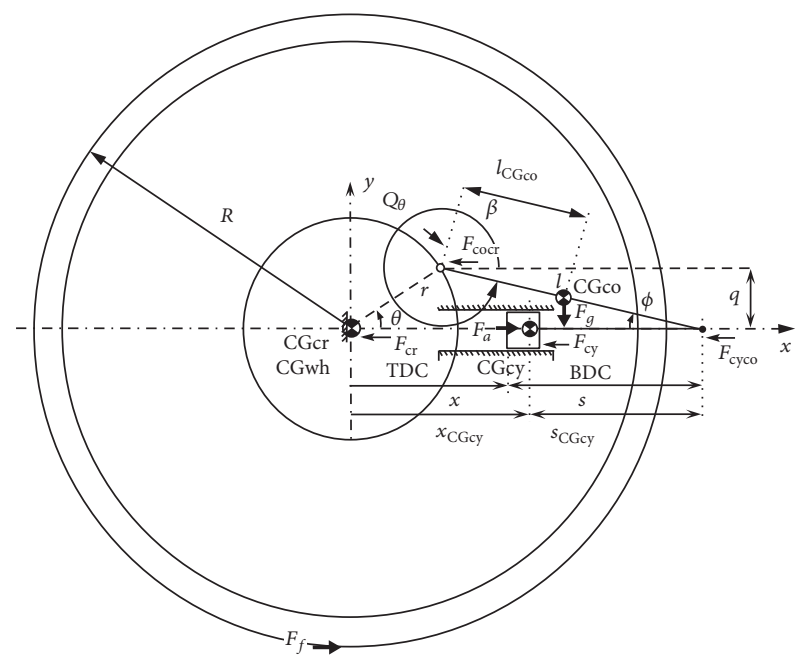

FIgURE 1: Schematic draw of a compressed air engine composed of pneumatic cylinder and a crank-connecting-rod.

to its CG in the plane $x y$ ( $\left.x_{\mathrm{CGcy}}\right)$ through the length of CG $\left(s_{\mathrm{CGcy}}\right)$ can be described as presented in

$$
x_{\mathrm{CGcy}}=r \cos \theta+l \cos \phi-s_{\mathrm{CGcy}} .
$$

In the way to determine the linear position of $\left(x_{\mathrm{CGcy}}\right)$ in relation to the angular position of the crank $\theta$ and the linear speed of the cylinder, the following geometrical relations are made out as presented in (2) to (4) [20].

$$
\begin{aligned}
q & =r \sin \theta=l \sin \phi \\
\sin \phi & =\frac{r}{l} \sin \theta \\
\cos \phi & =\left(1-\sin ^{2} \phi\right)^{1 / 2}=\left(1-\left(\frac{r}{l} \sin \theta\right)^{2}\right)^{1 / 2} \\
x_{\mathrm{CGcy}} & =r \cos \theta+l\left(1-\frac{r^{2}}{l^{2}} \sin ^{2} \theta\right)^{1 / 2}-s_{\mathrm{CGcy}} \\
& =r \cos \theta+\left(l^{2}-r^{2} \sin ^{2} \theta\right)^{1 / 2}-s_{\mathrm{CGcy}} \\
v_{\mathrm{CGcy}} & =\dot{\theta}\left(-r \sin \theta-\frac{r^{2} \sin \theta \cos \theta}{\left(l^{2}-r^{2} \sin ^{2} \theta\right)^{1 / 2}}\right) .
\end{aligned}
$$

In kinematics, (5) presents the ( $\left.x_{\mathrm{CGcy}}\right)$ position in relation to $\theta$ and (6) shows the ( $\left.v_{\mathrm{CGcy}}\right)$ linear velocity, which is further used to calculate the kinetic energy.

2.1. The Modelling of the Governing Equations of Motion. In this subsection, the mathematical equations that emulate the motion of the nonlinear connecting-rod-crank system with horizontal geometry and monocylinder motor are developed using the energy method of Lagrange, where its function is represented by

$$
\mathscr{L}(\theta, \dot{\theta}, t)=T-V
$$


The Lagrangian is expressed in terms of the generalized coordinate $\theta$, the masses concentrated in the CG of each link, the geometry, and the rigid materials. Therefore, the equation of Euler-Lagrange is described as (8), where $Q_{\theta}$ represents the nonconservative forces.

$$
\frac{d}{d t}\left(\frac{\partial \mathscr{L}}{\partial \dot{\theta}}\right)-\frac{\partial \mathscr{L}}{\partial \theta}=Q_{\theta} .
$$

In this way, the resulting force $F_{\mathrm{R}}$ composed of the nonconservative forces in function of the virtual displacement can be obtained by the virtual work of

$$
\begin{aligned}
Q_{\theta} & =F_{\mathrm{R}}\left(\frac{\partial x_{\mathrm{CGcy}}}{\partial \theta}\right) \\
& =F_{\mathrm{R}}\left(-r \sin \theta-\frac{r^{2} \sin \theta \cos \theta}{\left(l^{2}-r^{2} \sin ^{2} \theta\right)^{1 / 2}}\right),
\end{aligned}
$$

where

$$
F_{\mathrm{R}}=F_{\mathrm{a}}-F_{\mathrm{f}}-F_{\text {cae }} .
$$

The nonconservative force $F_{\text {cae }}$ is considered as a damping force, considering the whole damping forces of the system, which are $F_{\text {cy }} ; F_{\text {cyco }} ; F_{\text {cocr }}$, and $F_{\text {cr }}$ (Figure 1). Moreover, the compressed air engine is considered as a viscous-damping, that is, a relation proportional to the angular velocity of the wheel of the system multiplied by a constant, as given by

$$
F_{\text {cae }}=c_{\text {cae }} \dot{\theta} .
$$

The $F_{\mathrm{a}}$ force is another dissipative force of the system. It is provided due to two dissipative forces of the system, one is from the own motion of the mechanism, and the other is from the transmission of the wheel motion to the bicycle, which dissipate energy of the system. The connecting-rod crank system is excited by the air force of the pneumatic pressure via a control signal to a pressure regulator valve. Therefore, the air force $F_{\mathrm{a}}$ is proportional to the area of the cylinder and air pressure $P_{\mathrm{a}}$ determined by the control SDRE, given by

$$
P_{\mathrm{a}}\left(x_{1}\right)=\frac{F_{\mathrm{a}}\left(x_{1}\right)}{\left(\pi\left(d^{2} / 4\right)\right)},
$$

where $P_{\mathrm{a}}$ is the nonconservative pressure which generates the force $F_{\mathrm{a}}$ of the air that excites the movement of the system with $d$ being the cylinder diameter of the compressed air engine.

The friction force $F_{\mathrm{f}}$ depends on the pressure, tire section, and wheel length, as much as the type of the contact surface. The considered value to this resistance force of the bearing is approximately $9 \mathrm{~N}$ to big section tires and $2.3 \mathrm{~N}$ to racing tires of thin section, low friction, and high performance [21]. $F_{\mathrm{f}}$ is proportional to the normal force $\left(F_{\mathrm{N}}\right)$, whose component is generated by the angle of inclination of the ground $(\beta)$ applied to the mass of the bike $\left(m_{\mathrm{b}}\right)$ and the mass of the cyclist $\left(m_{\mathrm{c}}\right)$ as function of gravity $(g)$. Therefore, (13) depends on the rolling coefficient $\left(c_{\mathrm{r}}\right)$ in function of the masses which varies with the following types of parameters: bearings, ground, tire, and hoop, as well as tire pressure [22].

$$
\begin{aligned}
F_{\mathrm{f}} & =c_{\mathrm{r}} \cos (\psi) \\
F_{\mathrm{N}} & =c_{\mathrm{r}} \cos (\psi)\left(m_{\mathrm{c}}+m_{\mathrm{b}}\right) g .
\end{aligned}
$$

In this way, all forces relation of (8) of Euler-Lagrange to the calculus of resulting work of nonconservative forces was defined. However, to determine the full equations of motion, it is needed to estimate the conservative forces and energies that balance the mechanism movement. Thus, for the analysis of the equilibrium of the conservative forces, the kinetic energy $T$ for translational movements and rotation of the inertial restrictions of the mechanism must be calculated. Therefore, the CG of each link is used as a way to interpret the individual motions of each link, in function of its links and combined restrictions. Each link moves by rotation and translation motions or still with their combination around their CG. The potential energy $V$ is evaluated by its contribution from the gravitational potential energy, favoring or not the movement of each position of the links. Therefore, the Lagrangian of the system is calculated for the energies of the three links that have movements in relation to the fixed link of the mechanism, as follows:

$$
\mathscr{L}=\left(T_{\text {cy }}+T_{\text {cr }}+T_{\text {co }}\right)-\left(V_{\text {co }}+V_{\text {cr }}+V_{\text {cy }}\right) .
$$

The kinetic energy $T_{\mathrm{cy}}$ of the monocylinder possesses an inertia for the translation movement equivalent to that of a cylindrical bar. The kinetic energy $T_{c r}$ of the crank possesses an inertia of the rotation movement equivalent to that of a solid cylinder/disk (shaft and crank connection) and thin hoop (wheel and radius). The kinetic energy $T_{\text {co }}$ of the connecting-rod has inertia of the rotation movement equivalent to that of a solid cylinder/disk (shaft and crank connection) and thin hoop (wheel and radius). The gravitational potential energy $V_{\text {co }}$ of the connecting-rod is generated by the vertical movement of its mass $m_{c o}$ on the twodimensional plane $x y$. However, the gravitational potential energies $V_{\text {cy }}$ and $V_{\text {cr }}$ do not consider vertical movement of their masses on the two-dimensional plane $x y$, then not generating potential energy.

Therefore, one should calculate the kinetic energy of all links of the mechanism in function of their masses and only the potential gravitational energy of the connectingrod, which is the unique link that generates vertical motion. The kinetic energy of the crank just considered the rotational motion, because the crank possesses a rigid coupling with the wheel by means of hoops free to rotate through the bearing coupled to the fixed link of the mechanism. Thus, the calculus of the kinetic energy of the crank is defined as an inertial system equivalent to a solid cylinder and disk for the shaft and the crank combined with the inertia of thin hoops for the wheel and your radius, as follows:

$$
\begin{aligned}
T_{\mathrm{cr}} & =\frac{1}{2}\left(\left(\frac{1}{2}\left(\left(m_{\mathrm{cr}}\right)(r)^{2}\right) \dot{\theta}^{2}\right)+\left(\left(\left(m_{\mathrm{ra}}\right)\left(\frac{R}{2}\right)^{2}\right) \dot{\theta}^{2}\right)\right. \\
& \left.+\left(\left(\left(m_{\mathrm{wh}}\right)(R)^{2}\right) \dot{\theta}^{2}\right)\right) .
\end{aligned}
$$


For the calculus of energies it is necessary to define the geometry for the components because the masses generate the moment of inertia equivalent to the components of the compressed air engine. Thus, the mass $m_{\mathrm{cr}}$ related to the moment of inertia is equivalent to a solid cylinder (shaft) and a disk (crank) related to the geometry and radius $(r)$. The mass $m_{\mathrm{ra}}$ related to the moment of inertia is equivalent to a thin hoop with the distribution in function of the wheel middle radius $(R / 2)$. The mass $m_{\text {wh }}$ related to the moment of inertia is equivalent to a thin hoop for the hoop of the wheel with tire which is related to the wheel radius $(R)$. The mass $m_{\mathrm{co}}$, which is related to the moment of inertia, is equivalent to a slender rod for the connecting-rod and is related to the crank and the cylinder through their angular and linear velocities. Moreover, the mass $m_{\mathrm{wh}}$ related to the moment of inertia is equivalent to a thin hoop for the hoop of the wheel with tire and is related to the wheel radius $(R)$.

However, the kinetic energy of the connecting-rod is calculated considering the momentum of inertia of the masses as to rotational motion and to translational motion, and the connecting-rod possesses two degrees-of-freedom of motion in $x y$ plane. Thus, the calculation of the kinetic energy of the connecting-rod was defined as an equivalent inertia system to a slender rod with axis through end, rotating and translating during the motion in the plane $x y$, as given by

$$
\begin{aligned}
& T_{\mathrm{co}} \\
& \quad=\frac{1}{2}\left(\left(\left(m_{\mathrm{co}}\right) v_{\mathrm{CGco}}{ }^{2}\right)+\left(\left(\frac{1}{3}\left(m_{\mathrm{co}}\right)\left(\frac{l}{2}\right)^{2}\right) \dot{\beta}^{2}\right)\right) .
\end{aligned}
$$

Transforming the energy equations in terms of generalized coordinates, trigonometric relations are used to the angles of $\theta$ and $\beta$ (congruent and obtuse) to use in relative velocity of the connecting-rod in function of the generalized coordinates. As the connecting-rod link is a two-degreesof-freedom system, there is two relative velocities related to the crank and its coordinate $\theta$. Therefore, the relative velocity of the connecting-rod considers the translational and rotational motions which is developed by using the cosines' law, denoting $[23,24]$

$$
v_{\mathrm{CGco}}{ }^{2}=r^{2} \dot{\theta}^{2}+l_{\mathrm{CGco}}{ }^{2} \dot{\beta}^{2}+2 r l_{\mathrm{CGco}} \cos (\theta-\beta) \dot{\theta} \dot{\beta},
$$

where

$$
\begin{aligned}
\cos (\theta-\beta) & =\cos \theta \cos \beta+\sin \theta \sin \beta \\
\cos \beta & =\cos \phi=\left(1-\left(\frac{r}{l} \sin \theta\right)^{2}\right)^{1 / 2} \\
& =\frac{\left(l^{2}-r^{2} \sin ^{2} \theta\right)^{1 / 2}}{l} \\
\sin \beta & =\left(-\frac{r}{l} \sin \theta\right) \\
\dot{\beta} & =-\dot{\theta}\left(\frac{r \cos \theta}{\left(l^{2}-r^{2} \sin ^{2} \theta\right)^{1 / 2}}\right) .
\end{aligned}
$$

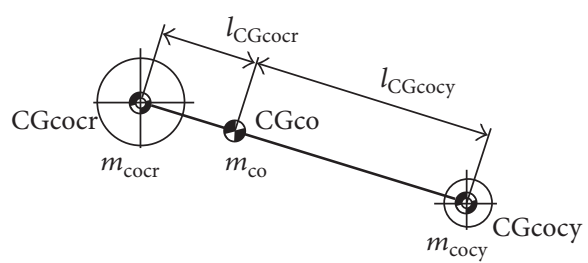

FIGURE 2: Equivalent dynamic model of concentrated masses of the connecting-rod.

However, because the relative velocity is a very complex term and may be spread in many terms to represent the kinetic energy of the connecting-rod, a simplification of the model is necessary and represents the movement of the system as much as using the complex term. Thus, the technique of concentrated masses of an equivalent dynamic model [20] can be applied when three requirements are evaluated to the dynamical equivalence, which are as follows: the final mass of the model must be equal to the total mass of the original link; the CG of connecting-rod must stay in the same original position of the link; the final momentum of inertia of the masses must be equal to the initial link, as shown in Figure 2.

Through this equivalent dynamic model of concentrated masses, the complex rotational and translation motions of the connecting-rod are converted into a rotational motion of the crank and a translational motion of the cylinder. This conversion generates equivalence when the place of the percussion centers of the equivalent masses related to the original link mass is determined. In the typical geometry of a typical connecting-rod, because its masses are higher to the forces of connection with the crank (width and height) its percussion center is closer to the connection extremity of the crank than the CG. Therefore, this geometry allows simplifying and concentrating the masses in the connections with the links and present an error relatively small in the precision of this dynamic model [20]. These connections with links are denoted by

$$
\begin{aligned}
& m_{\text {cocr }}=m_{\mathrm{co}} \frac{l_{\text {CGcocy }}}{\left(l_{\text {CGcocr }}+l_{\text {CGcocy }}\right)} \\
& m_{\text {cocy }}=m_{\text {co }} \frac{l_{\text {CGcocr }}}{\left(l_{\text {CGcocr }}+l_{\text {CGcocy }}\right)} .
\end{aligned}
$$

The connecting-rod of this work has typical geometry with CGco placed with $l_{\text {CGcocr }}$ to $1 / 3$ of the length $l$ of the connection with the crank and $l_{\text {CGcocy }}$ to $2 / 3$ of length $l$ of the connection to the cylinder. Introducing these lengths in (19), it is possible to obtain the partial value of the total of masses of the connecting-rod coupled to the links by the connections, as given by

$$
\begin{aligned}
& m_{\mathrm{cocr}}=m_{\mathrm{co}} \frac{(2 / 3) l}{((1 / 3) l+(2 / 3) l)}=m_{\mathrm{co}} \frac{2}{3} l \\
& m_{\mathrm{cocy}}=m_{\mathrm{co}} \frac{(1 / 3) l}{((1 / 3) l+(2 / 3) l)}=m_{\mathrm{co}} \frac{1}{3} l .
\end{aligned}
$$


This geometric distribution for the connecting-rod results in the equivalent masses for application on the crank with the equivalent mass $m_{\text {cocr }}$ equal to $1 / 3$ of $m_{\text {co }}$ and the equivalent mass to application in the cylinder $m_{\text {cocy }}$ equal to $2 / 3$ of $m_{\text {co }}$. In this way of distribution of applied masses to the links of crank (20) and cylinder (21), with their pure motions of rotation and translation, possibilities of the obtainment of the kinetic energy equivalent of the connecting-rod link are given by

$$
\begin{gathered}
T_{\text {co }}=\frac{1}{2}\left(\left(\left(m_{\text {cocy }}\right) v_{\mathrm{CGcy}}^{2}\right)+\left(\left(\frac{1}{3}\left(m_{\text {cocr }}\right)(r)^{2}\right) \dot{\theta}^{2}\right)\right) \\
=\frac{1}{2}\left(\left(\left(\frac{m_{\mathrm{co}}}{3}\right) v_{\mathrm{CGcy}}^{2}\right)+\left(\left(\frac{1}{3}\left(\frac{2 m_{\mathrm{co}}}{3}\right)(r)^{2}\right) \dot{\theta}^{2}\right)\right) .
\end{gathered}
$$

The kinetic energy of the cylinder is also considered the translational movement. The angular position $\theta$ used (6), which determines the linear position of the cylinder CG in function of the crank's rotational angle. Thus, the kinetic energy of the monocylinder is given by

$$
\begin{aligned}
T_{\mathrm{cy}} & =\frac{1}{2}\left(\left(m_{\mathrm{cy}}\right) v_{\mathrm{CGcy}}{ }^{2}\right) \\
& =\frac{1}{2}\left(\left(m_{\mathrm{cy}}\right) \dot{\theta}^{2}\left(-r \sin \theta-\frac{r^{2} \sin \theta \cos \theta}{\left(l^{2}-r^{2} \sin ^{2} \theta\right)^{1 / 2}}\right)^{2}\right) .
\end{aligned}
$$

The potential gravitational energy is given by the connecting-rod link, which possesses the CG motion related to the vertical displacement that generates a variation of energy in relation to the position variation. By geometry, the potential gravitation energy is considered as a vertical projection of $l_{\text {CGco }}$ to the variation of the CG position of the connection-rod link in function of the gravitational force, given by

$$
\begin{aligned}
V_{\text {co }} & =\left(m_{\text {co }}\right) g\left(\frac{2 l}{3} \sin \phi\right)=\left(m_{\text {co }}\right) g\left(\frac{2 l}{3} \frac{r}{l} \sin \theta\right) \\
& =\left(m_{\text {co }}\right) g\left(\frac{2 r}{3} \sin \theta\right) .
\end{aligned}
$$

Therefore, (24) can be rewritten in function of the gravitational constant force, given by

$$
V_{\mathrm{co}}=F_{\mathrm{g}}\left(\frac{2 r}{3} \sin \theta\right) \text {. }
$$

Substituting the energy terms into (14) in terms of their derivatives and applying Euler-Lagrange equation (8), the governing equation of motion of the crank-connecting-rod system in function of the conservatives and nonconservative forces are obtained and are written in state-space form as (26), where $\theta=x_{1}, \dot{\theta}=\dot{x}_{1}=x_{2}$, and $\ddot{\theta}=\ddot{x}_{1}=\dot{x}_{2}$.

$$
\begin{aligned}
\dot{x}_{1}= & x_{2} \\
\dot{x}_{2}= & x_{2}^{2}\left(\delta\left(x_{1}\right) \varepsilon\left(x_{1}\right)\right)+x_{2}\left(\delta\left(x_{1}\right) \varsigma\left(x_{1}\right)\right) \\
& +\left(\delta\left(x_{1}\right)\left(F_{\mathrm{a}}\left(x_{1}\right) \zeta\left(x_{1}\right)+\xi\left(x_{1}\right)\right)\right),
\end{aligned}
$$

where

$$
\begin{aligned}
& \delta\left(x_{1}\right)=1 \times\left(( m _ { \mathrm { wh } } ) \left(36 \sin x_{1}{ }^{4} R^{2} r^{4}\right.\right. \\
& \left.-72 \sin x_{1}{ }^{2} R^{2} l^{2} r^{2}+36 R^{2} l^{4}\right)+\left(m_{\mathrm{ra}}\right) \\
& +\left(9 \sin x_{1}{ }^{4} R^{2} r^{4}-18 \sin x_{1}{ }^{2} R^{2} l^{2} r^{2}+9 R^{2} l^{4}\right) \\
& +\left(m_{\mathrm{cr}}\right)\left(18 \sin x_{1}{ }^{4} r^{6}-36 \sin x_{1}{ }^{2} l^{2} r^{4}+18 l^{4} r^{2}\right) \\
& +\left(m_{\mathrm{co}}\right)\left(-12 \cos x_{1}{ }^{2} \sin x_{1}{ }^{4} r^{8}+12 \sin x_{1}{ }^{6} r^{8}\right. \\
& +12 \cos x_{1}{ }^{2} \sin x_{1}{ }^{2} l^{2} r^{6}-24 \sin x_{1}{ }^{4} l^{2} r^{6} \\
& +24 \lambda\left(x_{1}\right)^{3 / 2} \cos x_{1} \sin x_{1}{ }^{2} r^{5}+8 \sin x_{1}{ }^{4} r^{6} \\
& \left.+12 \sin x_{1}{ }^{2} l^{4} r^{4}-16 \sin x_{1}{ }^{2} l^{2} r^{4}+8 l^{4} r^{2}\right)+\left(m_{\mathrm{cy}}\right) \\
& +\left(-36 \cos x_{1}{ }^{2} \sin x_{1}{ }^{4} r^{6}+36 \sin x_{1}{ }^{6} r^{6}\right. \\
& +36 \cos x_{1} \sin x_{1}{ }^{2} l^{2} r^{4}-72 \sin x_{1}{ }^{4} l^{2} r^{4} \\
& +72 \cos x_{1} \sin x_{1}{ }^{2} \lambda\left(x_{1}\right)^{3 / 2} r^{3} \\
& \left.\left.+36 \sin x_{1}{ }^{2} l^{4} r^{2}\right)\right)^{-1}
\end{aligned}
$$$$
\varepsilon\left(x_{1}\right)=\left(( m _ { \mathrm { cy } } ) \left(-72 \cos x_{1} \sin x_{1}{ }^{5} r^{6}\right.\right.
$$$$
-36 \lambda\left(x_{1}\right)^{1 / 2} \cos x_{1}{ }^{2} \sin x_{1}{ }^{3} r^{5}
$$$$
-36 \cos x_{1}^{3} \sin x_{1} l^{2} r^{4}+108 \cos x_{1} \sin x_{1}{ }^{3} l^{2} r^{4}
$$$$
-72 \lambda\left(x_{1}\right)^{3 / 2} \cos x_{1}^{2} \sin x_{1} r^{3}
$$$$
\left.+36 \lambda\left(x_{1}\right)^{3 / 2} \sin x_{1}{ }^{3} r^{3}-36 \cos x_{1} \sin x_{1} l^{4} r^{2}\right)
$$$$
+\left(m_{\mathrm{co}}\right)\left(-24 \cos x_{1} \sin x_{1}^{5} r^{8}\right.
$$$$
-12 \lambda\left(x_{1}\right)^{1 / 2} \cos x_{1}{ }^{2} \sin x_{1}{ }^{3} r^{7}
$$$$
-12 \cos x_{1}{ }^{3} \sin x_{1} l^{2} r^{6}+36 \cos x_{1} \sin x_{1}{ }^{3} l^{2} r^{6}
$$$$
-24 \cos x_{1}{ }^{2} \sin x_{1} \lambda\left(x_{1}\right)^{3 / 2} r^{5}
$$$$
\left.\left.+12 \sin x_{1}{ }^{3} \lambda\left(x_{1}\right)^{3 / 2} r^{5}-12 \cos x_{1} \sin x_{1} l^{4} r^{4}\right)\right)
$$$$
\varsigma\left(x_{1}\right)=\left(-36 c_{\mathrm{cae}} \eta\left(x_{1}\right) r^{4} \sin x_{1}{ }^{4}+72 c_{\mathrm{cae}} \eta\left(x_{1}\right) r^{2}\right.
$$$$
\left.\cdot \sin x_{1}^{2} l^{2}-36 c_{\mathrm{cae}} \eta\left(x_{1}\right) l^{4}\right)
$$$$
\zeta\left(x_{1}\right)=\left(36 \sin x_{1}{ }^{4} r^{4} \eta\left(x_{1}\right)-72 \sin x_{1}{ }^{2} l^{2} r^{2} \eta\left(x_{1}\right)\right.
$$$$
\left.+36 l^{4} \eta\left(x_{1}\right)\right)
$$$$
\xi\left(x_{1}\right)=\left(F _ { \mathrm { g } } \left(-24 r^{5} \cos x_{1} \sin x_{1}^{4}\right.\right.
$$$$
\left.+48 r^{3} \cos x_{1} \sin x_{1}{ }^{2} l^{2}-24 r \cos x_{1} l^{4}\right)
$$ 


$$
\begin{aligned}
& +F_{\mathrm{f}}\left(-36 \sin x_{1}{ }^{4} r^{4} \eta\left(x_{1}\right)+72 \sin x_{1}{ }^{2} l^{2} r^{2} \eta\left(x_{1}\right)\right. \\
& \left.\left.-36 l^{4} \eta\left(x_{1}\right)\right)\right)
\end{aligned}
$$

where $\lambda\left(x_{1}\right)=\left(l^{2}-r^{2} \sin x_{1}^{2}\right)$ and $\eta\left(x_{1}\right)=$ $\left(-r \sin x_{1}\left(\left(-r^{2} \sin x_{1} \cos x_{1}\right) / \lambda\left(x_{1}\right)^{1 / 2}\right)\right)$.

The application of the controller consists of substituting the excitation torque generated by the air force $F_{\mathrm{a}}$ induced by the pressure $P_{\mathrm{a}}(12)$, for the control signal $\mathbf{U}$, given by

$$
\mathbf{U}=F_{\mathrm{a}} \zeta\left(x_{1}\right) .
$$

Introducing the control signal in (26), it has the equation of motion with the control system which can be denoted by

$$
\begin{aligned}
\dot{x}_{1}= & x_{2} \\
\dot{x}_{2}= & x_{2}^{2}\left(\delta\left(x_{1}\right) \varepsilon\left(x_{1}\right)\right)+x_{2}\left(\delta\left(x_{1}\right) \varsigma\left(x_{1}\right)\right) \\
& +\left(\delta\left(x_{1}\right)\left(\mathbf{U}+\xi\left(x_{1}\right)\right)\right) .
\end{aligned}
$$

The control vector $\mathbf{U}$ consists of two parts; $\mathbf{U}_{\mathrm{fe}}$ and $\mathbf{U}_{\mathrm{fo}}=$ $-\varphi\left(x_{1}\right)$, where $\mathbf{U}_{\mathrm{fo}}$ is the feedforward control and $\mathbf{U}_{\mathrm{fe}}$ is the feedback control obtained through the SDRE control signal, as show in

$$
\mathbf{U}=\mathbf{U}_{\mathrm{fe}}+\mathbf{U}_{\mathrm{fo}}=\mathbf{U}_{\mathrm{fe}}-\xi\left(x_{1}\right) .
$$

Therefore, changing the notation of the control signal $\mathbf{U}=$ $\mathbf{U}_{\mathrm{fe}}+\mathbf{U}_{\mathrm{fo}}$ in (29), the final equation of motion of the controlled system can be rewritten by the form of

$$
\begin{aligned}
\dot{x}_{1}= & x_{2} \\
\dot{x}_{2}= & x_{2}^{2}\left(\delta\left(x_{1}\right) \varepsilon\left(x_{1}\right)\right)+x_{2}\left(\delta\left(x_{1}\right) \varsigma\left(x_{1}\right)\right) \\
& +\left(\delta\left(x_{1}\right)\left(\mathbf{U}_{\mathrm{fe}}\right)\right) .
\end{aligned}
$$

From (31), the movement of the system can be controlled by the angular velocity $\dot{\theta}=\dot{x}_{1}=x_{2}$, being the main control variable, similar to an automatic vehicular driver. The application of the control variables and description of the process by the method of SDRE and PD controls will be detailed in the next section.

2.2. SDRE Control Design. The technique of SDRE control by nonlinear feedback has been applied in many nonlinear problems, estimating the states satisfying the aiming functions [25-28]. The SDRE controller uses the LQR (Linear Quadratic Regulator) method to find the suboptimal gain in function of State-Dependent Riccati Equations, recalculating them along with the application on nonlinear systems of (32) [11].

Therefore, the equation of motion of the crank-connecting-rod of (31) can be rewritten in matrix form as given by

$$
\dot{\mathbf{X}}=\mathbf{A}(\mathbf{X}) \mathbf{X}+\mathbf{B}(\mathbf{X}) \mathbf{U}_{\mathrm{fe}},
$$

where

$$
\begin{aligned}
& \mathbf{A}=\left[\begin{array}{lc}
0 & 1 \\
0 & \left(x_{2}\left(\delta\left(x_{1}\right)\left(\varepsilon\left(x_{1}\right)\right)\right)+\left(\delta\left(x_{1}\right) \varsigma\left(x_{1}\right)\right)\right)
\end{array}\right] \\
& \mathbf{X}=\left[\begin{array}{l}
x_{1} \\
x_{2}
\end{array}\right] \\
& \mathbf{B}=\left[\begin{array}{c}
0 \\
\delta\left(x_{1}\right)
\end{array}\right] .
\end{aligned}
$$

The quadratic performance measure for the feedback control $\left(\mathbf{U}_{\mathrm{fe}}\right)$ problem is given by

$$
\mathbf{J}=\int_{0}^{\infty}\left(\mathbf{e}_{S}^{T} \mathbf{Q} \mathbf{e}_{S}+\mathbf{U}_{\mathrm{fe}}^{T} \mathbf{R} \mathbf{U}_{\mathrm{fe}}\right) d t
$$

where $\mathbf{e}_{S}=\left[\begin{array}{l}x_{1}-x_{1}^{*} \\ x_{2}-x_{2}^{*}\end{array}\right], x_{1}^{*}$ is the desired orbit, $x_{2}^{*}$ is the desired velocity, and $\mathbf{Q}(\mathbf{x})$ and $\mathbf{R}(\mathbf{x})$ are positive definite matrices. The minimization of functional (34) implies the minimization of the system deviation (32) of the desired state $\left(\mathbf{e}_{S}=\left[\begin{array}{l}x_{1}-x_{1}^{*} \\ x_{2}-x_{2}^{*}\end{array}\right]\right)$ and of the applied feedback control $\left(\mathbf{U}_{\mathrm{fe}}\right)$. Assuming full-state feedback $\left(\mathbf{U}_{\mathrm{fe}}\right)$, the control law is given by [29]

$$
\mathbf{U}_{\mathrm{fe}}=\mathbf{R}^{-1} \mathbf{B}(\mathbf{X})^{\mathrm{T}} \mathbf{P}(\mathbf{X}) \mathbf{e}_{S},
$$

where $\mathbf{P}(\mathbf{X})$ is the solution of the Riccati equation:

$$
\begin{aligned}
\mathbf{A}(\mathbf{X})^{\mathbf{T}} \mathbf{P}(\mathbf{X})+\mathbf{P}(\mathbf{X}) \mathbf{A}(\mathbf{X}) \\
\quad-\mathbf{P}(\mathbf{X}) \mathbf{B}(\mathbf{X}) \mathbf{R}^{-\mathbf{1}} \mathbf{B}(\mathbf{X})^{\mathrm{T}} \mathbf{P}(\mathbf{X})+\mathbf{Q}=\mathbf{0} .
\end{aligned}
$$

Another important factor to consider is that the matrix $\mathbf{A}(\mathbf{X})$ cannot violate the controllability of the system. Crankconnecting-rod system (32) is controllable if the rank of the matrix $\mathbf{M}$ is 2:

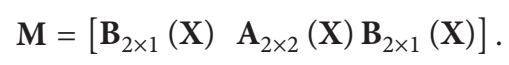

The SDRE technique to obtain a suboptimal solution for dynamic control problem has the following procedure [29]:

(1) Define the state-space model with the state-dependent coefficients $\mathbf{A}(\mathbf{X})$ and $\mathbf{B}(\mathbf{X})$.

(2) Define the initial condition $\mathbf{x}(\mathbf{0})=\mathbf{x}_{\mathbf{0}}$ so that the rank of $\mathbf{M}$ is $n$ and choose the coefficients of weight matrices $\mathbf{Q}$ and $\mathbf{R}$, where the matrices $\mathbf{Q}$ and $\mathbf{R}$ determine the relative importance of parameter error and energy expenditure.

(3) Solve $\mathbf{P}(\mathbf{X})$ for the Riccati equation which will be described in the sequence of this method for the states as a function of time.

(4) Define $\mathbf{e}_{S}$ the objective functions for the calculation of the parameter errors.

(5) Calculate the input signal $\mathbf{U}_{\mathrm{fe}}$.

(6) Integrate the equation obtained in step (1) and update the state of the system as a function of time with the results. 
(7) Calculate the rank of step (2) and if rank = 2 go to step (3). However, if rank $<2$, the matrix $\mathbf{A}(\mathbf{X})$ is not controllable; therefore, you should use the last matrix controllable $\mathbf{A}(\mathbf{X})$ that has been obtained, and thus go to step (3).

2.3. PD Control Design. The PD control comprises one control loop which regulates the suspension travel. The PD controller operates according to the following equation [1719]:

$$
\mathbf{U}_{\mathrm{fe}}=k_{p} e_{x_{1}}(t)+k_{d} e_{x_{2}}(t),
$$

where $e_{x_{2}}=d e_{x_{1}}(t) / d t, e_{x_{1}}=x_{1}-x_{1}{ }^{*}$, and $e_{x_{2}}=x_{2}-x_{2}{ }^{*}$ and $k_{p}$ is the proportional gain and $k_{d}$ is the derivative gain of the loop control, respectively.

For the determination of $k_{p}$ and $k_{d}$ gains, the autotuning of the PD gains of the MathWorks ${ }^{\circledR}$ algorithm is considered. To PD controllers, the MathWorks algorithm adjusts gains for good balance between performance and robustness [30].

\section{Numerical Results and Discussions}

With the objective of keeping the angular velocity of the crank constant, similar to an automatic vehicular driver, the application of the control signal will be considered in a way to keep the angular velocity $x_{2}{ }^{*}(8.415 \mathrm{rad} / \mathrm{s}, 16.83 \mathrm{rad} / \mathrm{s}$, and $25.245 \mathrm{rad} / \mathrm{s}$ ), and such velocity in the crank axis provides a velocity of $10 \mathrm{~km} / \mathrm{h}, 20 \mathrm{~km} / \mathrm{h}$, and $30 \mathrm{~km} / \mathrm{h}$. Considering the initial conditions $x_{1}(0)=\pi \mathrm{rad}$ and $x_{2}(0)=0 \mathrm{rad} / \mathrm{s}$, it is possible to estimate $x_{1}^{*}$ as $x_{1}^{*} \approx x_{2}^{*} t+4.67$.

The application of the control signal $\mathbf{U}=\mathbf{U}_{\mathrm{fe}}+\mathbf{U}_{\mathrm{fo}}$ will be considered two cylinders connected to the same connection with the connecting-rod; that is, two cylinders will be applied in symmetric form related to the $y$-axis.

$F_{\mathrm{f}}$ obtained from (13) to asphalt floor rolling with tubular tire $22 \mathrm{~g} 700 \times 23 \mathrm{~mm}$ with $275 \mathrm{kPa}$ of pressure will be considered, with the following parameters [31-33]: cyclist mass $72 \mathrm{~kg}$, bicycle mass $18 \mathrm{~kg}$, and rolling coefficient $c_{\mathrm{r}}=$ 0.006 .

After these initial considerations, the parameters that will be used for numerical simulations are listed in Table 1, whose values are physical parameters of the connecting-rod crank system.

Hence, considering the equation of motion obtained in (32) and using the parameters of Table 1 and implementing the control signal, numerical simulations are shown in the following. The numerical simulations are carried out using the method of Runge-Kutta of 4 th order with a fixed step of $h=0.001$.

3.1. Numerical Results for SDRE Control. To determine the feedback control $\left(\mathbf{U}_{\mathrm{fe}}\right)$ used in (32) of the motion we consider the following initial conditions and matrices: $x_{1}(0)=\pi \mathrm{rad}$, $x_{2}(0)=0 \mathrm{rad} / \mathrm{s}, \mathbf{Q}=\left[\begin{array}{cc}1 & 0 \\ 0 & 1000\end{array}\right]$, and $\mathbf{R}=[1]$.

Figure 3 shows the results of the system of (32) applying the SDRE control signal $\mathbf{U}$ with its results for states $\left(x_{1}\right.$ and $\left.x_{2}\right)$ and velocity error $\left(e_{x_{2}}\right)$ obtained for the case with constant velocity of $25.245 \mathrm{rad} / \mathrm{s}(30 \mathrm{~km} / \mathrm{h})$.
TABLE 1: Parameters for simulation.

\begin{tabular}{lcc}
\hline Parameter & Value & Unit (SI) \\
\hline$r$ & 0.10 & $\mathrm{~m}$ \\
$l$ & 0.30 & $\mathrm{~m}$ \\
$R$ & 0.33 & $\mathrm{~m}$ \\
$d$ & 0.025 & $\mathrm{~m}$ \\
$S_{\text {CGcy }}$ & 0.12 & $\mathrm{~m}$ \\
$m_{\mathrm{c}}$ & 80 & $\mathrm{~kg}$ \\
$m_{\mathrm{b}}$ & 18 & $\mathrm{~kg}$ \\
$m_{\mathrm{cy}}$ & 0.34 & $\mathrm{~kg}$ \\
$m_{\mathrm{co}}$ & 0.55 & $\mathrm{~kg}$ \\
$m_{\mathrm{cr}}$ & 1.00 & $\mathrm{~kg}$ \\
$m_{\mathrm{ra}}$ & 0.50 & $\mathrm{~kg}$ \\
$m_{\mathrm{wh}}$ & 2.50 & $\mathrm{~kg}$ \\
$F_{\mathrm{f}}$ & 5.77 & $\mathrm{~N}$ \\
$c_{\mathrm{r}}$ & 0.006 & - \\
$c_{\text {cae }}$ & 0.02 & $\mathrm{~N} \cdot \mathrm{s} / \mathrm{rad}$ \\
$g$ & 9.81 & $\mathrm{~m} / \mathrm{s}$ \\
$\psi$ & 0 & $\mathrm{Degrees}\left({ }^{\circ}\right)$ \\
$x_{1}(0)$ & $\pi$ & $\mathrm{rad}$ \\
$x_{2}(0)$ & 0 & $\mathrm{rad} / \mathrm{s}$ \\
\hline
\end{tabular}

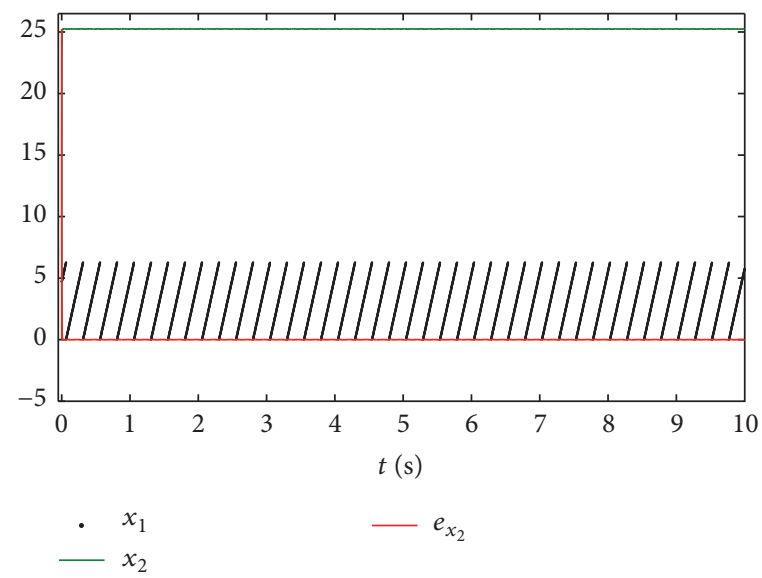

FIGURE 3: Double-cylinder with SDRE control by position and constant velocity $\left(x_{2}{ }^{*}=25.245 \mathrm{rad} / \mathrm{s}=30 \mathrm{~km} / \mathrm{h}\right)$.

Figure 4 shows the results normalized for the case with constant velocity of $25.245 \mathrm{rad} / \mathrm{s}(30 \mathrm{~km} / \mathrm{h})$, and to obtain the real values it is needed to multiply $\mathbf{U}$ for $638 \mathrm{~N} \cdot \mathrm{m}, P_{\mathrm{a}}$ for $80200 \mathrm{kPa}$, and $F_{\mathrm{a}}$ for $39368.17 \mathrm{~N}$.

The maximum value of control signal was $0.58 \mathrm{Nm}(0.92 \times$ $\left.10^{-3} \times 638\right)$ to steady state and the maximum applied pressure was $240.60 \mathrm{kPa}\left(3 \times 10^{-3} \times 80200\right)$ which generates a maximum force of $118.10 \mathrm{~N}\left(3 \times 10^{-3} \times 39368.17\right)$ in pressure peaks (Figure 4). However, there is another pressure peak during the cycle of $2 \pi$ of rotation which is of $80.20 \mathrm{kPa}\left(1 \times 10^{-3} \times\right.$ $80200)$ and it generates a maximum force of $39.37 \mathrm{~N}\left(1 \times 10^{-3} \times\right.$ 39368.17).

The pressures and forces values were obtained through applying (28), (29), (30), and (31) which generates the 


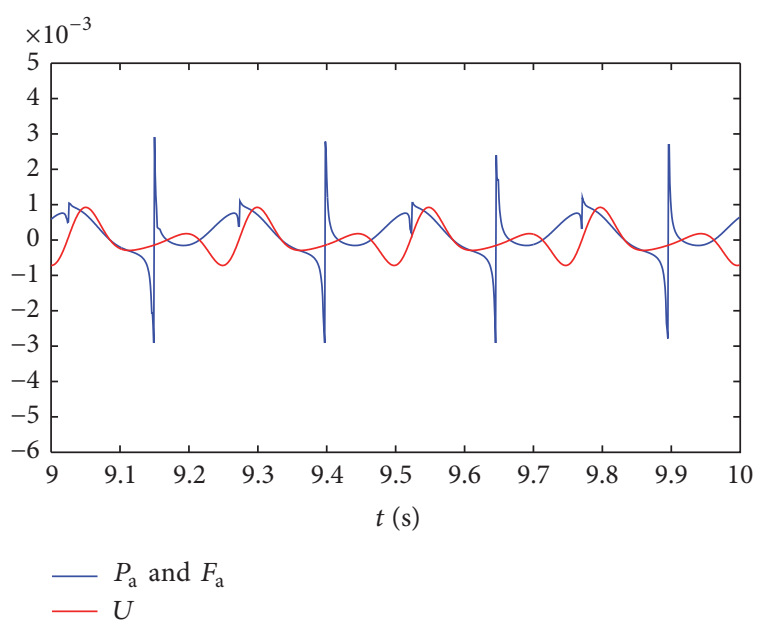

FIGURE 4: SDRE control signal for constant velocity $\left(x_{2}{ }^{*}=\right.$ $25.245 \mathrm{rad} / \mathrm{s}=30 \mathrm{~km} / \mathrm{h}$ ) with double-cylinder excited by pressure (normalized).

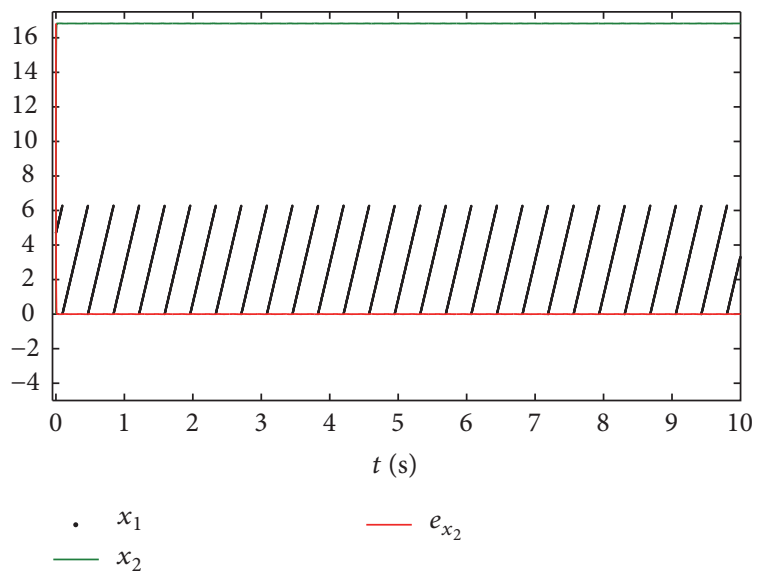

FIGURE 5: Double-cylinder with SDRE control by position and constant velocity $\left(x_{2}{ }^{*}=16.83 \mathrm{rad} / \mathrm{s}=20 \mathrm{~km} / \mathrm{h}\right)$.

excitation force $F_{\mathrm{a}}$ converted into pressure $P_{\mathrm{a}}$ through (12). This variation of force does not impact on the motor and its machinery elements for there are the characteristics of compressibility and damping of energy by compressed air with the overpressure being equalized during the movement.

Figure 5 shows the results of the system of (32) applying the control signal $\mathbf{U}$ of SDRE with their results for the states $\left(x_{1}\right.$ and $\left.x_{2}\right)$ and the velocity error $\left(e_{x_{2}}\right)$ obtained for the case with constant velocity of $16.83 \mathrm{rad} / \mathrm{s}(20 \mathrm{~km} / \mathrm{h})$.

Figure 6 shows the results normalized for the case with constant velocity of $16.83 \mathrm{rad} / \mathrm{s}(20 \mathrm{~km} / \mathrm{h})$, and to obtain the real values it is needed to multiply $\mathbf{U}$ for $426 \mathrm{~N} \cdot \mathrm{m}, P_{\mathrm{a}}$ for $56400 \mathrm{kPa}$, and $F_{\mathrm{a}}$ for $27685.35 \mathrm{~N}$.

The maximum value of the control signal was $0.36 \mathrm{Nm}$ $\left(0.85 \times 10^{-3} \times 426\right)$ to steady state which generates a maximum applied pressure of $225.6 \mathrm{kPa}\left(4 \times 10^{-3} \times 56400\right)$ and a maximum force of $110.7 \mathrm{~N}\left(4 \times 10^{-3} \times 27685.35\right)$ in pressure peaks (Figure 6). However, there is another pressure peak during the cycle of $2 \pi$ of rotation which is $25.9 \mathrm{kPa}(0.46 \times$

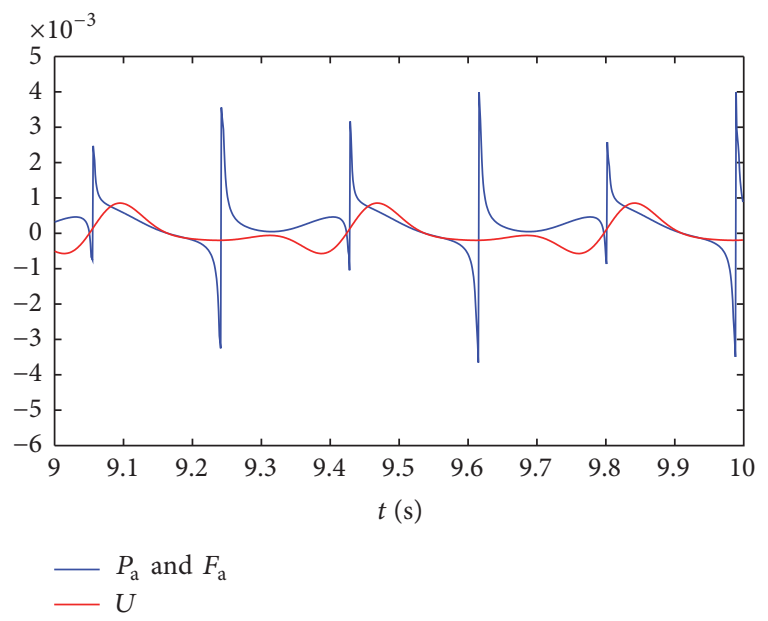

FIGURE 6: SDRE signal control to constant velocity $\left(x_{2}{ }^{*}=\right.$ $16.83 \mathrm{rad} / \mathrm{s}=20 \mathrm{~km} / \mathrm{h}$ ) with double-cylinder excited by pressure (normalized).

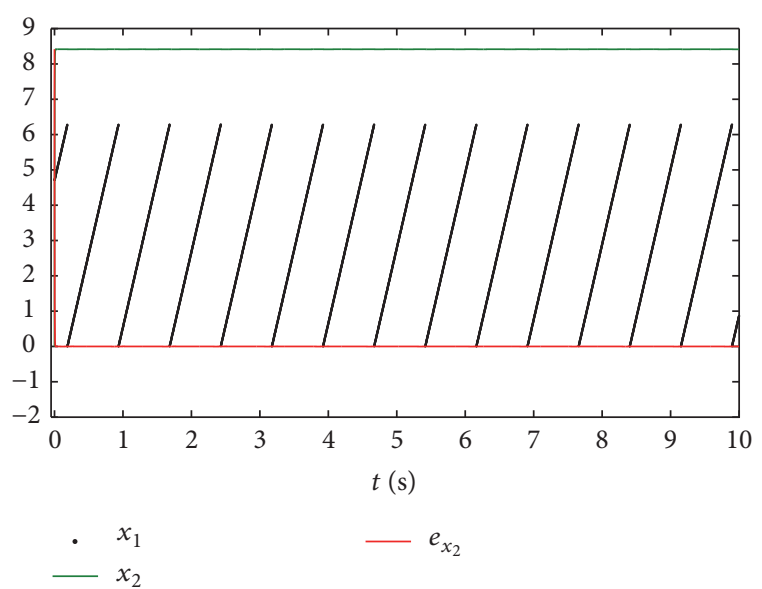

FIgURE 7: Double-cylinder with SDRE control by position and constant velocity $\left(x_{2}{ }^{*}=8.415 \mathrm{rad} / \mathrm{s}=10 \mathrm{~km} / \mathrm{h}\right)$.

$\left.10^{-3} \times 56400\right)$ and generates a force of $12.73 \mathrm{~N}\left(0.46 \times 10^{-3} \times\right.$ 27685.35).

Figure 7 shows the results of the system of (32) applying the SDRE control signal $\mathbf{U}$ with their results for the states $\left(x_{1}\right.$ and $\left.x_{2}\right)$ and the velocity error $\left(e_{x_{2}}\right)$ obtained for the case with velocity constant of $8.415 \mathrm{rad} / \mathrm{s}(10 \mathrm{~km} / \mathrm{h})$.

Figure 8 shows the results normalized for the case with constant velocity of $8.415 \mathrm{rad} / \mathrm{s}(10 \mathrm{~km} / \mathrm{h})$, and to obtain the real values it is needed to multiply $\mathbf{U}$ for $213 \mathrm{~N} \cdot \mathrm{m}, P_{\mathrm{a}}$ for $37400 \mathrm{kPa}$, and $F_{\mathrm{a}}$ for $18358.72 \mathrm{~N}$.

The maximum value of the control signal was $0.213 \mathrm{Nm}$ $\left(1 \times 10^{-3} \times 213\right)$ to steady state which generates a maximum applied pressure of $205.7 \mathrm{kPa}\left(5.5 \times 10^{-3} \times 37400\right)$ and a maximum force of $100.97 \mathrm{~N}\left(5.5 \times 10^{-3} \times 13358.72\right)$ in pressure peaks (Figure 8 ). However, there is another pressure peak during the cycle of $2 \pi$ of rotation which is $10.84 \mathrm{kPa}(0.29 \times$ $\left.10^{-3} \times 37400\right)$ and it generates a force of $5.32 \mathrm{~N}\left(0.29 \times 10^{-3} \times\right.$ 18358.72). 


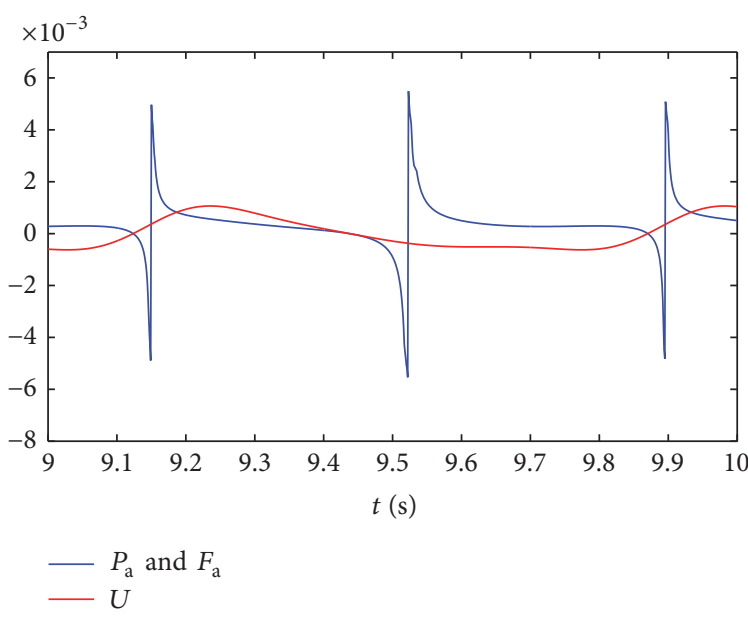

FIGURE 8: SDRE control signal to constant velocity $\left(x_{2}{ }^{*}=\right.$ $8.415 \mathrm{rad} / \mathrm{s}=10 \mathrm{~km} / \mathrm{h}$ ) with double-cylinder excited by pressure (normalized).

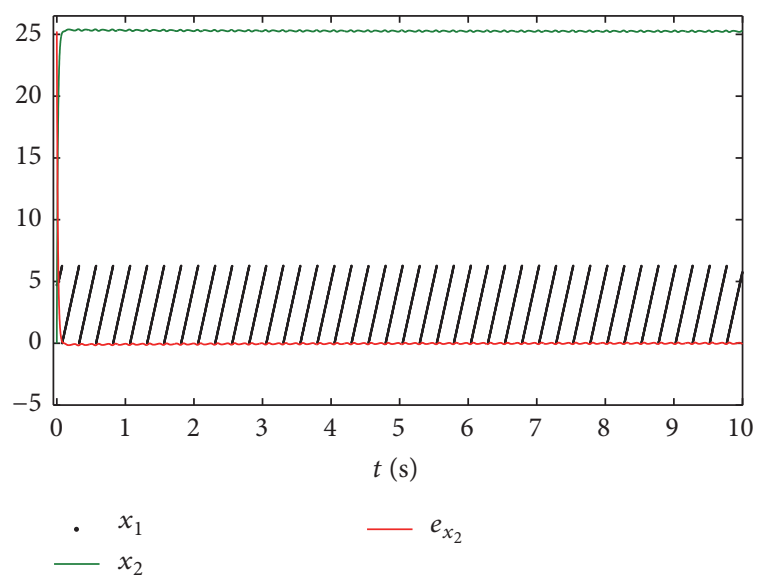

FIGURE 9: Double-cylinder with PD control by position and constant velocity $\left(x_{2}{ }^{*}=25.245 \mathrm{rad} / \mathrm{s}=30 \mathrm{~km} / \mathrm{h}\right)$.

3.2. Numerical Results for PD Control. Considering (33) and parameters of Table 1 , autotuning of $\mathrm{PD}$ gains of the MathWorks algorithm obtains $k_{p}=-1.4$ and $k_{d}=$ -4.3 . Substituting the gains in (38), the feedback control is obtained:

$$
\mathbf{U}_{\mathrm{fe}}=-1.4\left(x_{1}-x_{1}^{*}\right)-4.3\left(x_{2}-x_{2}^{*}\right) .
$$

Figure 9 shows the results of the system of (32) applying the PD control signal $\mathbf{U}$ with their results for the states $\left(x_{1}\right.$ and $\left.x_{2}\right)$ and the velocity error $\left(e_{x_{2}}\right)$ obtained for the case with constant velocity of $25.245 \mathrm{rad} / \mathrm{s}(30 \mathrm{~km} / \mathrm{h})$.

Figure 10 shows the results normalized at steady state for the case with constant velocity of $25.245 \mathrm{rad} / \mathrm{s}(30 \mathrm{~km} / \mathrm{h})$, and to obtain the real values it is needed to multiply $\mathrm{U}$ for $105 \mathrm{~N} \cdot \mathrm{m}$, $P_{\mathrm{a}}$ for $54000 \mathrm{kPa}$, and $F_{\mathrm{a}}$ for $26507.25 \mathrm{~N}$.

The maximum value of control signal was $0.44 \mathrm{Nm}(4.2 \times$ $\left.10^{-3} \times 105\right)$ at steady state which generates a maximum applied pressure of $378 \mathrm{kPa}\left(7 \times 10^{-3} \times 54000\right)$ and a maximum force of $185.55 \mathrm{~N}\left(7 \times 10^{-3} \times 23507.25\right)$ in pressure peaks

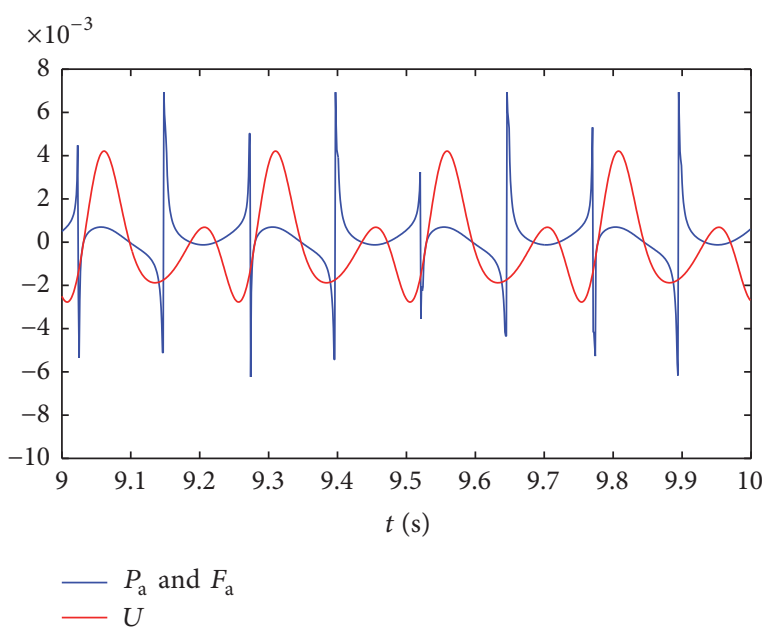

FIGURE 10: PD control signal for constant velocity $\left(x_{2}{ }^{*}=\right.$ $25.245 \mathrm{rad} / \mathrm{s}=30 \mathrm{~km} / \mathrm{h}$ ) with double-cylinder excited by pressure (normalized).

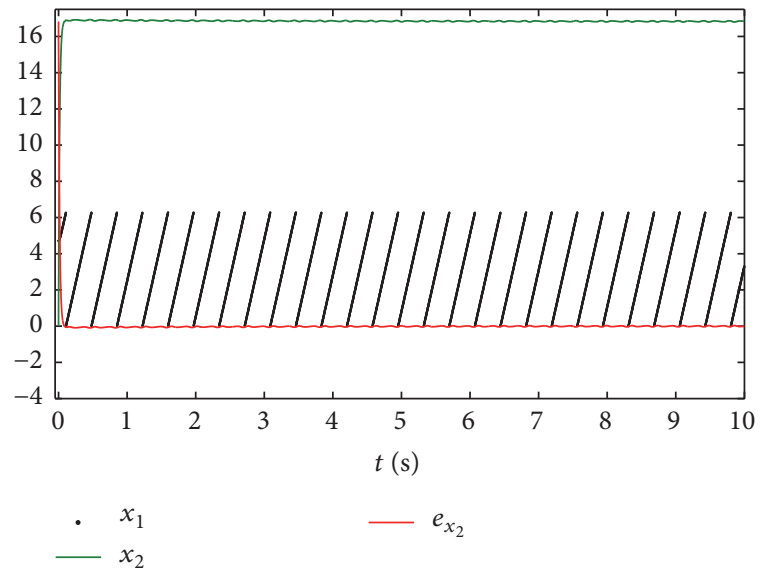

FIgURE 11: Double-cylinder with PD control by position and constant velocity $\left(x_{2}{ }^{*}=16.83 \mathrm{rad} / \mathrm{s}=20 \mathrm{~km} / \mathrm{h}\right)$.

(Figure 10). However, there is another pressure peak during the cycle of $2 \pi$ of rotation which is $37.8 \mathrm{kPa}\left(0.7 \times 10^{-3} \times 54000\right)$ and it generates a maximum force of $18.55 \mathrm{~N}\left(0.7 \times 10^{-3} \times\right.$ 26507.25).

Figure 11 shows the results of the system of (32) applying the PD control signal $\mathbf{U}$ with their results for the states $\left(x_{1}\right.$ and $\left.x_{2}\right)$ and the velocity error $\left(e_{x_{2}}\right)$ obtained for the case with velocity constant of $16.83 \mathrm{rad} / \mathrm{s}(20 \mathrm{~km} / \mathrm{h})$.

Figure 12 shows the results normalized for the case with constant velocity of $16.83 \mathrm{rad} / \mathrm{s}(20 \mathrm{~km} / \mathrm{h})$, and to obtain the real values it is needed to multiply $\mathbf{U}=70 \mathrm{Nm}, P_{\mathrm{a}}$ for $39000 \mathrm{kPa}$, and $F_{\mathrm{a}}$ for $19144.12 \mathrm{~N}$.

The maximum value of control signal was $0.33 \mathrm{Nm}(4.7 \times$ $\left.10^{-3} \times 70\right)$ at steady state which generates a maximum applied pressure of $312 \mathrm{kPa}\left(8 \times 10^{-3} \times 39000\right)$ and a maximum force of $153.15 \mathrm{~N}\left(8 \times 10^{-3} \times 19144.12\right)$ in pressure peaks (Figure 12). However, there is another pressure peak during the cycle of 


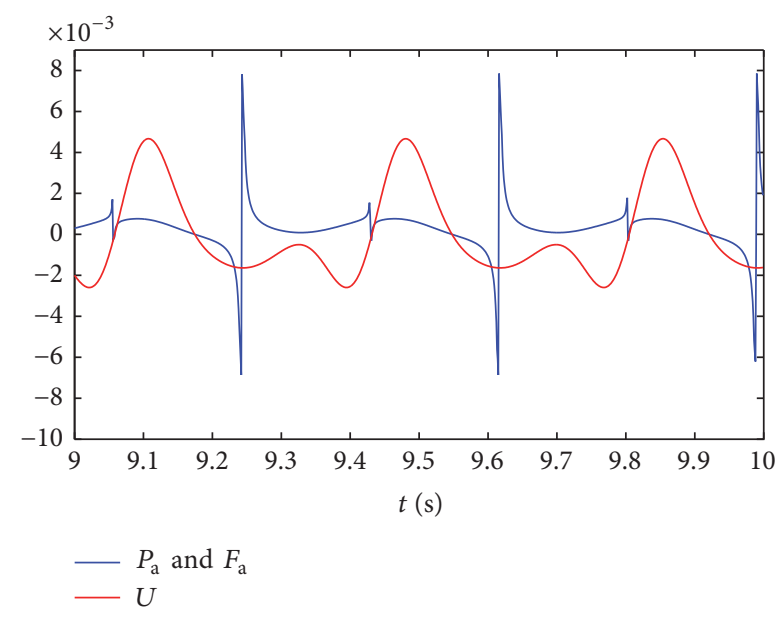

FIGURE 12: PD control signal for constant velocity $\left(x_{2}{ }^{*}=16.83 \mathrm{rad} / \mathrm{s}\right.$ $=20 \mathrm{~km} / \mathrm{h}$ ) with double-cylinder excited by pressure (normalized).

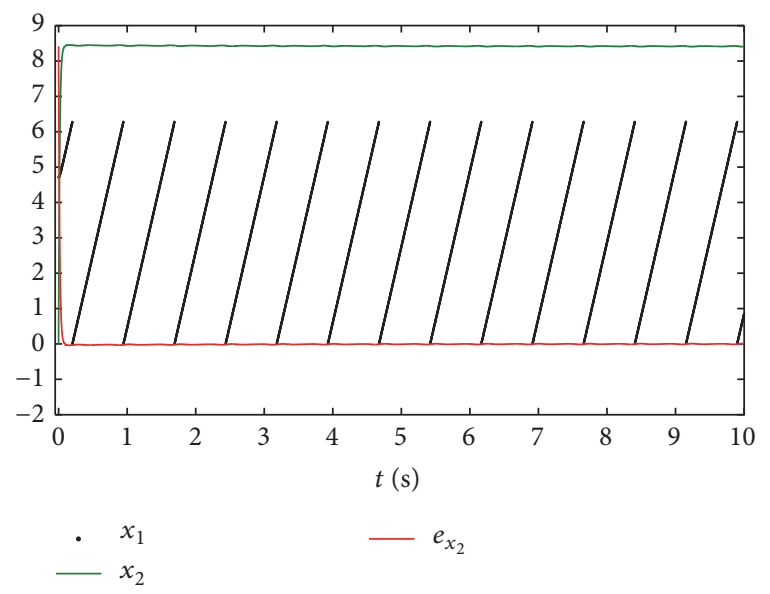

Figure 13: Double-cylinder with PD control by position and constant velocity $\left(x_{2}{ }^{*}=8.415 \mathrm{rad} / \mathrm{s}=10 \mathrm{~km} / \mathrm{h}\right)$.

$2 \pi$ of rotation which is $37.8 \mathrm{kPa}\left(0.7 \times 10^{-3} \times 54000\right)$ and it generates a maximum force of $18.55 \mathrm{~N}\left(0.7 \times 10^{-3} \times 26507.25\right)$.

Figure 13 shows the results of the system of (32) applying PD control signal $U$ with their results for the states $\left(x_{1}\right.$ and $\left.x_{2}\right)$ and the velocity error $\left(e_{x_{2}}\right)$ obtained for the case with constant velocity of $8.415 \mathrm{rad} / \mathrm{s}(10 \mathrm{~km} / \mathrm{h})$.

Figure 14 shows the results normalized for the case with constant velocity of $8.415 \mathrm{rad} / \mathrm{s}(10 \mathrm{~km} / \mathrm{h})$, and to obtain the real values it is needed to multiply $\mathbf{U}$ for $34.9 \mathrm{~N} \cdot \mathrm{m}, P_{\mathrm{a}}$ for $21400 \mathrm{kPa}$, and $F_{\mathrm{a}}$ for $10504.72 \mathrm{~N}$.

The maximum value of control signal was $0.22 \mathrm{Nm}$ $(0.0065 \times 34.9)$ at steady state which generates a maximum applied pressure of $235.4 \mathrm{kPa}(0.011 \times 21400)$ and a maximum force of $115.55 \mathrm{~N}(0.011 \times 10504.72)$ in pressure peaks (Figure 14). However, there is another pressure peak during the cycle of $2 \pi$ of rotation which is $10.7 \mathrm{kPa}(0.0005 \times 21400)$ and it generates a maximum force of $5.25 \mathrm{~N}(0.0005 \times 10504.72)$.

3.3. Discussions for SDRE and PD Control. The results of the previous sections showed that the control strategy composed

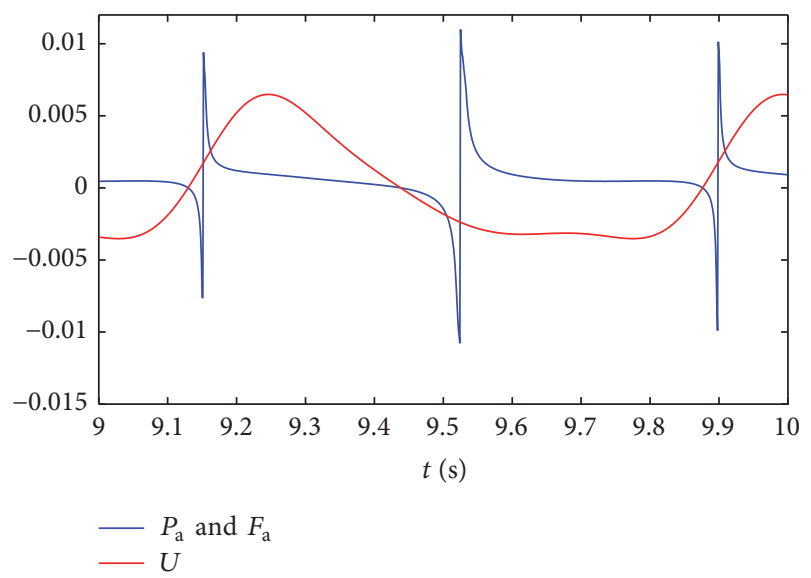

FIGURE 14: PD control signal for constant velocity $\left(x_{2}{ }^{*}=8.415 \mathrm{rad} / \mathrm{s}\right.$ $=10 \mathrm{~km} / \mathrm{h}$ ) with double-cylinder excited by pressure (normalized).

of feedback and feedforward controls is efficient in controlling the systems of both orbits $\left(x_{1}^{*}\right.$ and $\left.x_{2}^{*}\right)$ and that both SDRE and PD controls were efficient in leading the system to a desired orbit.

In this subsection the performance of the controllers will be considered considering RMS (Root Mean Square) of the absolute error and absolute errors in steady state.

Figure 15 shows the absolute error variation for the three studied cases $x_{2}{ }^{*}=8.415 \mathrm{rad} / \mathrm{s}, x_{2}{ }^{*}=16.83 \mathrm{rad} / \mathrm{s}$, and $x_{2}{ }^{*}=$ $25.245 \mathrm{rad} / \mathrm{s}$.

Considering the case that the desired velocity is $x_{2}{ }^{*}=8.415 \mathrm{rad} / \mathrm{s}$, it has SDRE control $\left|e_{x_{2}}\right|_{\mathrm{RMS} \text { SDRE }}=$ $0.000813 \mathrm{rad} / \mathrm{s}$ and error at steady state $e_{\mathrm{R} x_{2} \mathrm{SDRE}}=$ $0.017211 \%$. Considering PD control, it has $\left|e_{x_{2}}\right|_{\mathrm{RMS} \_\mathrm{PD}}=$ $0.005659 \mathrm{rad} / \mathrm{s}$ and error at steady state $e_{\mathrm{R} x_{2} \_\mathrm{PD}}=0.125564 \%$. As can be observed, the SDRE control has as well the absolute error as error at steady state smaller than that obtained with PD control, with the error at steady state to SDRE control being $86.1711 \%$ smaller than the error at steady state observed to PD control.

When the desired velocity is $x_{2}{ }^{*}=16.83 \mathrm{rad} / \mathrm{s}$, it has SDRE control $\left|e_{x_{2}}\right|_{\text {RMS_SDRE }}=0.003222 \mathrm{rad} / \mathrm{s}$ and error at steady state $e_{\mathrm{R} x_{2} \_\mathrm{SDRE}}=0.035152 \%$. Considering $\mathrm{PD}$ control, it has $\left|e_{x_{2}}\right|_{\mathrm{RMS} \_\mathrm{PD}}=0.019867 \mathrm{rad} / \mathrm{s}$ and error at steady state $e_{\mathrm{R} x_{2} \mathrm{PD}}=0.209257 \%$. As can be observed, the SDRE control has as well the absolute error as error at steady state smaller than that obtained with PD control, and the error at steady state to SDRE control is $83.20 \%$ smaller than the error at steady state observed to PD control.

Moreover, considering the case that the desired velocity is $x_{2}{ }^{*}=25.245 \mathrm{rad} / \mathrm{s}$, it has SDRE control $\left|e_{x_{2}}\right|_{\mathrm{RMS} \_\mathrm{SDRE}}=$ $0.007183 \mathrm{rad} / \mathrm{s}$ and error at steady state $e_{\mathrm{R} x_{2} \mathrm{SDRE}}=$ $0.051457 \%$. Considering PD control, it has $\left|e_{x_{2}}\right|_{\mathrm{RMS} \mathrm{PD}}=$ $0.03820 \mathrm{rad} / \mathrm{s}$ and error at steady state $e_{\mathrm{R} x_{2} \mathrm{PD}}=0.260022 \%$. As can be observed, the SDRE control has as well the absolute error as error at steady state smaller than that obtained with PD control, and the error at steady state to SDRE control is $80.21 \%$ smaller than the error at steady state observed to PD control. 


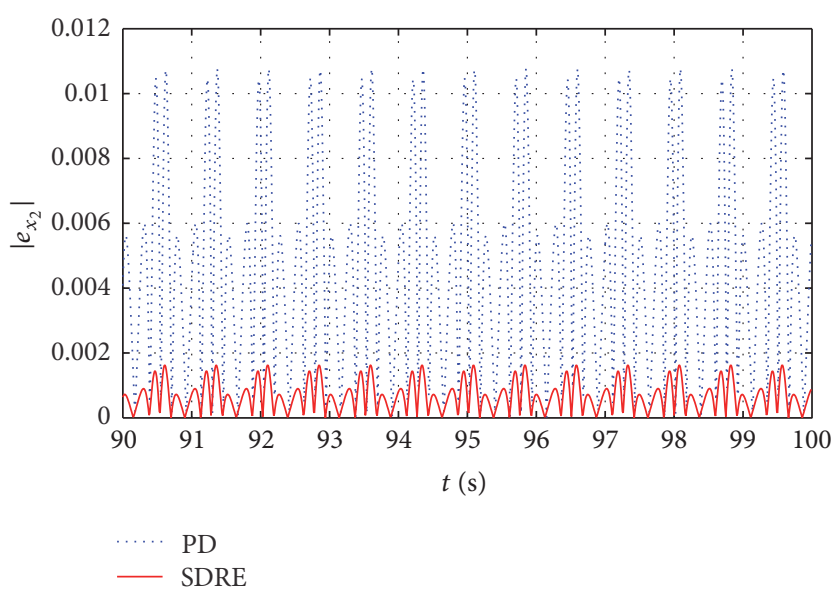

(a)

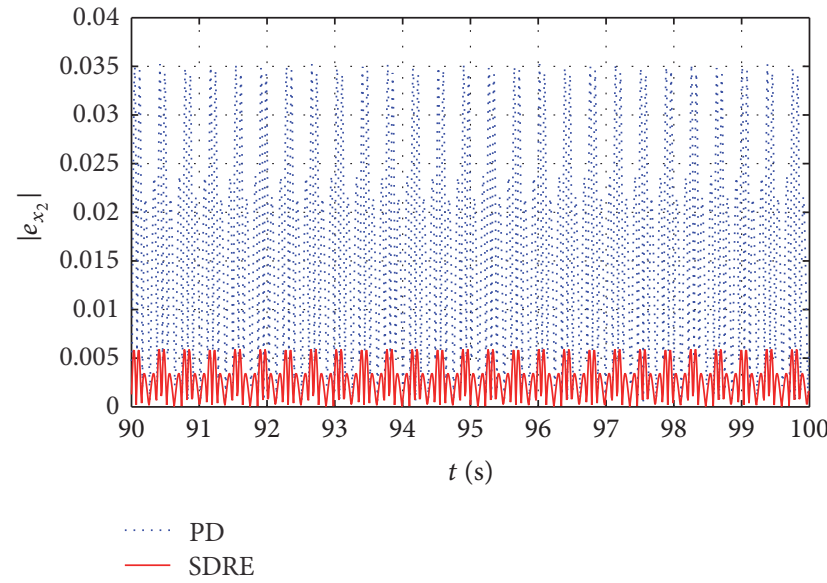

(b)

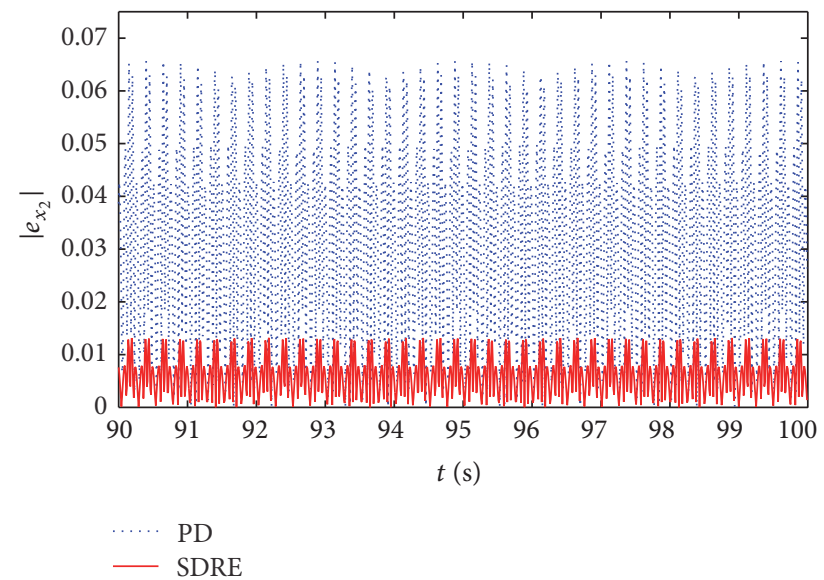

(c)

FIGURE 15: Absolute error variation $\left|e_{x_{2}}\right|=\left|x_{2}-x_{2}^{*}\right|$. (a) $\left|e_{x_{2}}\right|=\left|x_{2}-8.415\right|$. (b) $\left|e_{x_{2}}\right|=\left|x_{2}-16.83\right|$. (c) $\left|e_{x_{2}}\right|=\left|x_{2}-25.245\right|$.

Therefore, the next section shows the conclusions about this intense study.

\section{Conclusions}

In this work, a nonlinear dynamic model of a crank connecting-rod system modelled using the method of energy of Lagrange in function of its geometry was presented. Numerical simulations were carried out to the study of the dynamics of the system for SDRE and PD controls with the system showing to be controllable for the two controllers. The dynamic system was analyzed as a motor of double-cylinder, with excitation by pressure along all the period of rotation by means of pneumatic force.

To SDRE control, the peaks of force variated between 100 and $118 \mathrm{~N}$ and, to PD control, these peaks were higher with greater variation among the three velocities, varying from 115 to $185 \mathrm{~N}$. However, this higher difference of the peaks of force to PD controller is function of the pressure profile distributed along the course of the cylinder which uses fixed gains rather than variable ones being dependent on the applied states to SDRE control.
The geometry considered in this study has the potential of application with hybrid motor with the human biomechanical motive energy. However, the viability of production with pneumatic cylinders has to be considered, because they can be coupled to a bicycle wheel. In this way, due to being clean and possessing low weight as fuel, the pneumatic energy as a motor of rotational energies in wheels with traditional geometry remains as an alternative of application.

The efficiency of the PD controller to the nonlinear system showed an error of $0.12 \%(10 \mathrm{~km} / \mathrm{h})$ and $0.26 \%$ $(30 \mathrm{~km} / \mathrm{h})$ when applied as active control. In the case of the SDRE controller to the nonlinear system showed an error of $0.01 \%(10 \mathrm{~km} / \mathrm{h})$ and $0.05 \%(30 \mathrm{~km} / \mathrm{h})$. The error at steady state of SDRE control was $86.1711 \%(10 \mathrm{~km} / \mathrm{h})$ and $80.21 \%$ $(30 \mathrm{~km} / \mathrm{h})$ smaller in comparison to PD control.

Thus, the values of the errors showed that the velocity controlled presented low values with less than $0.038 \mathrm{rad} / \mathrm{s}$ for PD and $0.007 \mathrm{rad} / \mathrm{s}$ for SDRE control. In this way, both controllers presented viable final values of implementation in control of the automatic pilot to the pneumatic motor applied to a bicycle. However, to hybrid application of two motors with nonideal behavior, the SDRE control should provide 
a better performance in function of their characteristics of adaptation related to each state.

\section{Glossary}

$\oplus:$
$m_{\mathrm{wh}}:$
$\mathbf{P}(\mathbf{X}):$
$\mathbf{A}(\mathbf{X}):$
$P_{\mathrm{a}}:$
$\mathbf{B}(\mathbf{X}):$
$q:$
$c_{\mathrm{cae}}:$
Q:
$\mathrm{CGco}:$
$Q_{\theta}:$

CGcocr:

R:

CGcocy: Center of gravity and percussion of the mass of the crank relative to the connecting-rod

$R$ : $\quad$ Radius of the wheel with rigid connection to the crank link

CGwh = CGcr: Coincident CG of the wheel and crank with connect by bearings for the rotation

$r:$

CGcy:

$s:$

$c_{r}$ :

$s_{\mathrm{CGcy}}$ :

$d:$

$T:$

$\mathbf{e}_{S}$ :

Symbol which represents the Center of Percussion (CP)

Mass concentrated on the CG of the wheel Gravity (CG)

Matrix solution of the Riccati Equation for SDRE properties without influence on the control movement on the cylinder Matrix of the terms as a function of system properties with influence on the control geometry of the angles of the mechanism Viscous-damping coefficient of all damping forces in the compressed air engine importance of states and your errors CG of the connecting-rod with freedom of rotation and translation movement with the generalized coordinated applied the wheel $i$

Center of gravity and percussion of the mass of the cylinder relative to the connecting-rod

Matrix for relative importance of energy expenditure

Total length of the link crank

CG of the cylinder with freedom of translation movement

Total linear length of the cylinder link

Rolling coefficient of the bicycle in circumstances determined Linear length of the cylinder from the CG that connects to link connecting-rod Cylinder diameter of the compressed air engine

Kinetic energy for translational movements and rotation in function of the inertia

Matrix of angular position errors and velocity for SDRE control
$T_{\text {co }}: \quad$ Kinetic energy of the connecting-rod with inertia of the rotation movement

$e_{x_{1}}: \quad$ Value of the angular position error

$T_{\mathrm{cr}}$ : Kinetic energy of the crank with inertia of the rotation movement

$e_{x_{2}}: \quad$ Value of the angular velocity error

$T_{\text {cy }}$ : Kinetic energy of the monocylinder with inertia of the translation movement

$\left|e_{x_{2}}\right|_{\mathrm{RMS}}$ : Absolute error of the angular velocity using the Root Mean Square (RMS)

U: The total control signal for each case

$e_{\mathrm{R} x_{2}}$ : Maximum percentage error of the angular velocity using the Root Mean Square (RMS)

$\mathbf{U}_{\text {fo }}$ : The feedforward control for each case

$F_{\mathrm{a}}$ : $\quad$ Force of the air that excites the motion of the cylinder

$\mathbf{U}_{\mathrm{fe}}$ : Feedback control obtained through the PD or SDRE control signal

$F_{\text {cae }}$ : Resultant damping force equivalent of compressed air engine

$V: \quad$ Potential energy gravitational

$F_{\mathrm{cr}}: \quad$ Force that dissipates energy by rotating friction at the crank and the grounded link

$V_{\text {co }}$ Gravitational potential energy of the connecting-rod for the vertical motion

$F_{\text {cocr }}$ : Force that dissipates energy by rotating friction at the connecting-rod and the crank

$V_{\mathrm{cr}}: \quad$ Gravitational potential energy of the crank generated for the vertical motion

$F_{\text {cy }}$ : $\quad$ Force that dissipates energy by translation friction in the cylinder and the grounded link

$V_{\text {cy }}$ : Gravitational potential energy of the cylinder generated for the vertical motion

$F_{\text {cyco }}$ : Force that dissipates energy by rotating friction at the cylinder and the connecting-rod

$v_{\text {CGco }}$ : Linear velocity of the CG of the connecting-rod relative to the crank and cylinder velocities

$F_{\mathrm{f}}: \quad$ Force of friction transmitted by the wheel to the ground for the pure rolling on a bicycle

$v_{\mathrm{CGcy}}$ : Linear velocity of CG cylinder to the origin $x y$

$F_{\mathrm{g}}$ : Gravitational force that generates potential energy in the mechanism

Ẍ: Vector of angular acceleration

$F_{\mathrm{N}}$ : Normal force component for the angle $\beta$

$\dot{\mathrm{X}}$ : Vector of angular velocities

$F_{\mathrm{R}}$ : $\quad$ Nonconservative resultant force

X: $\quad$ Vector of angular positions

g: $\quad$ Acceleration of gravity

$x_{\text {CGcy }}$ : Linear position of CG cylinder to the origin $x y$

J: The cost functional of SDRE control 
$x y:$

$\mathbf{K}_{\mathrm{PD}}$ :

$\theta=x_{1}$ :

$\mathbf{K}_{\mathrm{S}}$ :

$\dot{\theta}=\dot{x}_{1}=x_{2}$ : Angular velocity of the link crank to the origin $x y$

$l: \quad$ Total length of the link connecting-rod

$\ddot{\theta}=\ddot{x}_{1}=\dot{x}_{2}$ : Angular acceleration of the link crank to the origin $x y$

$l_{\text {CGco }}$ : Length of the link connecting-rod to CG

$\theta^{*}=x_{1}{ }^{*}: \quad$ Desired angular position $x_{1}$

$l_{\text {CGcocr }}$ : Length of connecting-rod starting at the CG/CP the crank

$\dot{\theta}^{*}=x_{2}{ }^{*}: \quad$ Desired angular velocity $x_{2}$

$l_{\text {CGcocy }}$ : Length of connecting-rod starting at the CG/CP the cylinder

$\beta$ : $\quad$ Angular position of the connecting-rod with horizontal reference in relation to the crank

$\mathscr{L}$ : $\quad$ Function generated by Lagrangian mechanics

$\dot{\beta}: \quad$ Angular velocity of the connecting-rod with horizontal reference in relation to the crank

M: $\quad$ Controllability matrix

$\phi$ : $\quad$ Angular position of the connecting-rod with horizontal reference in relation to the cylinder

$m_{\mathrm{b}}$ : Bicycle's mass

$\psi: \quad$ Angle of inclination of the ground

$m_{\mathrm{c}}: \quad$ Cyclist's mass

$\delta\left(x_{1}\right): \quad$ Term of matrices $A(X)$ and $B(X)$ with parameters $\left(m_{\mathrm{wh}}, m_{\mathrm{ra}}, m_{\mathrm{cr}}, m_{\mathrm{co}}, m_{\mathrm{cy}}\right.$, and geometric) and variable $x_{1}$

$m_{\text {co }}$ : Mass concentrated on the CG of the connecting-rod relative to the link grounded

$\varepsilon\left(x_{1}\right): \quad$ Term of matrix $A(X)$ with parameters $\left(m_{\mathrm{co}}, m_{\mathrm{cy}}\right)$ and variable $x_{1}$

$m_{\text {cocr }}$ : Mass concentrated on the CG of the crank relative to the connecting-rod

$\varsigma\left(x_{1}\right): \quad$ Term of matrix $A(X)$ with parameters $\left(c_{\text {cae }}\right)$ and variable $x_{1}$

$m_{\text {cocy }}$ : Mass concentrated on the CG of the cylinder relative to the connecting-rod

$\zeta\left(x_{1}\right): \quad$ Term of matrix $A(X)$ with only the geometric parameters and variable $x_{1}$ which multiply $F_{\mathrm{a}}$

$m_{\mathrm{cr}}$ : $\quad$ Mass concentrated on the CG of the crank and shaft relative to the link grounded

$\xi\left(x_{1}\right)$ : $\quad$ Term of matrix $A(X)$ with parameters $\left(F_{\mathrm{g}}\right.$, $F_{\mathrm{f}}$ ) and variable $x_{1}$

$m_{\text {cy }}$ : $\quad$ Mass concentrated on the CG of the cylinder relative to the link grounded

$\lambda\left(x_{1}\right): \quad$ Term which simplifies geometric parameters and variable to the terms $\delta\left(x_{1}\right), \varepsilon\left(x_{1}\right), \varsigma\left(x_{1}\right), \zeta\left(x_{1}\right)$ and $\xi\left(x_{1}\right)$ $m_{\mathrm{ra}}: \quad$ Mass concentrated on the CG of the wheel middle radius relative to the link grounded

$\eta\left(x_{1}\right)$ : Term which simplifies geometric parameters and variable to the terms $\varsigma\left(x_{1}\right), \zeta\left(x_{1}\right)$ and $\xi\left(x_{1}\right)$.

\section{Conflicts of Interest}

The authors declare that there are no conflicts of interest regarding the publication of this paper.

\section{Acknowledgments}

The authors acknowledge support by CNPq (Grant 447539/ 2014-0), CAPES, and ARAUCÁRIA Foundation, all Brazilian research funding agencies.

\section{References}

[1] C. Bennett, J. F. Dunne, S. Trimby, and D. Richardson, "Engine cylinder pressure reconstruction using crank kinematics and recurrently-trained neural networks," Mechanical Systems and Signal Processing, vol. 85, pp. 126-145, 2017.

[2] M. S. Shadloo, R. Poultangari, M. Y. Abdollahzadeh Jamalabadi, and M. M. Rashidi, "A new and efficient mechanism for spark ignition engines," Energy Conversion and Management, vol. 96, article no. 6984, pp. 418-429, 2015.

[3] G. Shibata, K. Ishi, H. Ushijima, Y. Shibaike, H. Ogawa, and D. E. Foster, "Optimization of heat release shape and the connecting rod crank radius ratio for low engine noise and high thermal efficiency of premixed diesel engine combustion," SAE Technical Papers, 2015.

[4] A. H. Fathima and K. Palanisamy, "Optimization in microgrids with hybrid energy systems a review," Renewable and Sustainable Energy Reviews, vol. 45, pp. 431-446, 2015.

[5] A. Gabriel-Buenaventura and B. Azzopardi, "Energy recovery systems for retrofitting in internal combustion engine vehicles: a review of techniques," Renewable and Sustainable Energy Reviews, vol. 41, pp. 955-964, 2015.

[6] F. Wasbari, R. A. Bakar, L. M. Gan, M. M. Tahir, and A. A. Yusof, "A review of compressed-air hybrid technology in vehicle system," Renewable and Sustainable Energy Reviews, vol. 67, pp. 935-953, 2017.

[7] S. R. Pandian, Y. Hayakawa, Y. Kanazawa, Y. Kamoyama, and S. Kawamura, "Practical design of a sliding mode controller for pneumatic actuators," Journal of Dynamic Systems, Measurement, and Control, vol. 119, no. 4, pp. 666-674, 1997.

[8] Y. T. Shen and Y. R. Hwang, "Design and implementation of an air-powered motorcycles," Applied Energy, vol. 86, no. 7, pp. 1105-1110, 2009.

[9] R. B. Dudhat, N. R. Patel, V. M. Kanadiya, M. K. Mistry, and K. M. Joshi, "The investigational study of pragmatic model of compressed air single cylinder engine for increases the performance," in Proceedings of the International Journal of Advanced Engineering Technology, pp. 46-49, 2013.

[10] Y. W. Wang, J. J. You, C. K. Sung, and C. Y. Huang, "The applications of piston type compressed air engines on motor vehicles," Procedia Engineering, vol. 79, pp. 61-65, 2014.

[11] C. P. Mracek and J. R. Cloutier, "Control designs for the nonlinear benchmark problem via the state-dependent Riccati 
equation method," International Journal of robust and nonlinear control, vol. 8, pp. 401-433.

[12] A. Molter, O. A. A. Da Silveira, J. S. O. Fonseca, and V. Bottega, "Simultaneous piezoelectric actuator and sensor placement optimization and control design of manipulators with flexible links using SDRE method," Mathematical Problems in Engineering, vol. 2010, article 362437, pp. 1-23, 2010.

[13] A. M. Tusset, J. M. Balthazar, D. G. Bassinello, B. R. Pontes, and J. L. P. Felix, "Statements on chaos control designs, including a fractional order dynamical system, applied to a MEMS combdrive actuator," Nonlinear Dynamics, vol. 69, pp. 1837-1857, 2012.

[14] A. M. Tusset, J. M. Balthazar, and J. L. Felix, "On elimination of chaotic behavior in a non-ideal portal frame structural system, using both passive and active controls," Journal of Vibration and Control, vol. 19, no. 6, pp. 803-813, 2013.

[15] A. M. Tusset, A. M. Bueno, C. B. Nascimento, M. S. Kaster, and M. J. Balthazar, "Nonlinear state estimation and control for chaos suppression in MEMS resonator," Shock and Vibration, vol. 20, pp. 749-761, 2013.

[16] J. J. Lima, A. M. Tusset, F. C. Janzen et al., "Nonlinear state estimation and control applied to a manipulator robotic including drive motor," Mathematics in Engineering, Science and Aerospace, vol. 5, pp. 413-425, 2014.

[17] I. Salgado, I. Chairez, O. Camacho, and C. Yañe, "Super-twisting sliding mode differentiation for improving PD controllers performance of second order systems," ISA Transactions, vol. 53, no. 4, pp. 1096-1106, 2014.

[18] S. Yamacli and H. Canbolat, "Simulation of a SCARA robot with PD and learning controllers," Simulation Modelling Practice and Theory, vol. 16, no. 9, pp. 1477-1487, 2008.

[19] J. Zhang, S. Xu, and J. Li, "A new design approach of PD controllers," Aerospace Science and Technology, vol. 9, pp. 329336, 2005.

[20] R. L. Norton, Kinematics and Dynamics of Machinery, McGrawHill Higher Education, London, UK.

[21] E. R. Burke, Science of Cycling, Human Kinetics Publishers, 1st edition, 1986.

[22] F. R. Whitt and D. G. Wilson, Bicycle Science, MIT Press, Cambridge, UK, 2004.

[23] C. Boyle, L. L. Howell, S. P. Magleby, and M. S. Evans, "Dynamic modeling of compliant constant-force compression mechanisms," Mechanism and Machine Theory, vol. 38, no. 12, pp. 1469-1487, 2003.

[24] M. B. C. Yáñez, E. A. P. Flores, P. A. N. Suárez, G. S. Cervantes, and J. C. G. Robles, "Simulación dinámica de una transmisión de variación continúa," Scientia Et Technica, vol. 18, no. 1, pp. 108-113, 2013.

[25] A. M. Tusset, A. M. Bueno, C. B. Nascimento, M. dos Santos Kaster, and J. M. Balthazar, "Nonlinear state estimation and control for chaos suppression in MEMS resonator," Shock and Vibration, vol. 20, no. 4, pp. 749-761, 2013.

[26] J. M. Balthazar, D. G. Bassinello, A. M. Tusset, Á. M. Bueno, and B. R. de Pontes Junior, "Nonlinear control in an electromechanical transducer with chaotic behavior," Meccanica, vol. 49, no. 8 , pp. 1859-1867, 2014.

[27] J. J. De Lima, A. M. Tusset, F. C. Janzen et al., "SDRE applied to position and vibration control of a robot manipulator with a flexible link," Journal of Theoretical and Applied Mechanics, vol. 54, no. 4, pp. 1067-1078, 2016.
[28] A. Fenili, "The rigid-flexible robotic manipulator: nonlinear control and state estimation considering a different mathematical model for estimation," Shock and Vibration, vol. 20, no. 6, pp. 1049-1063, 2013.

[29] A. M. Tusset, V. Piccirillo, A. M. Bueno et al., "Chaos control and sensitivity analysis of a double pendulum arm excited by an RLC circuit based nonlinear shaker," Journal of Vibration and Control, vol. 22, no. 17, pp. 3621-3637, 2016.

[30] MATLAB 6.1, The MathWorks Inc., Natick, MA, https://www .mathworks.com/help/control/ug/design-compensator-usingautomated-tuning-methods.html? requestedDomain $=\mathrm{www}$ .mathworks.com, 2000.

[31] L. G. C. E. Pugh, “The relation of oxygen intake and speed in competition cycling and comparative observations on the bicycle ergometer," The Journal of Physiology, vol. 241, no. 3, pp. 795-808, 1974.

[32] A. C. Gross, R. K. Chester, and D. J. Malewicki, “The aerodynamics of human-powered land vehicles," Scientific American, vol. 249, no. 6, pp. 142-152, 1983.

[33] W. Hennekam, “The speed of a cyclist," Physics Education, vol. 25 , no. 3, pp. 141-146, 1990. 


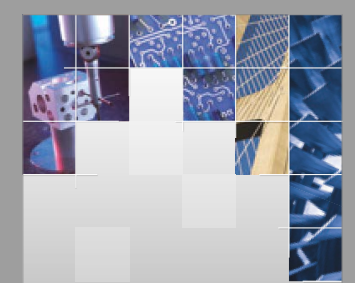

\section{Enfincering}
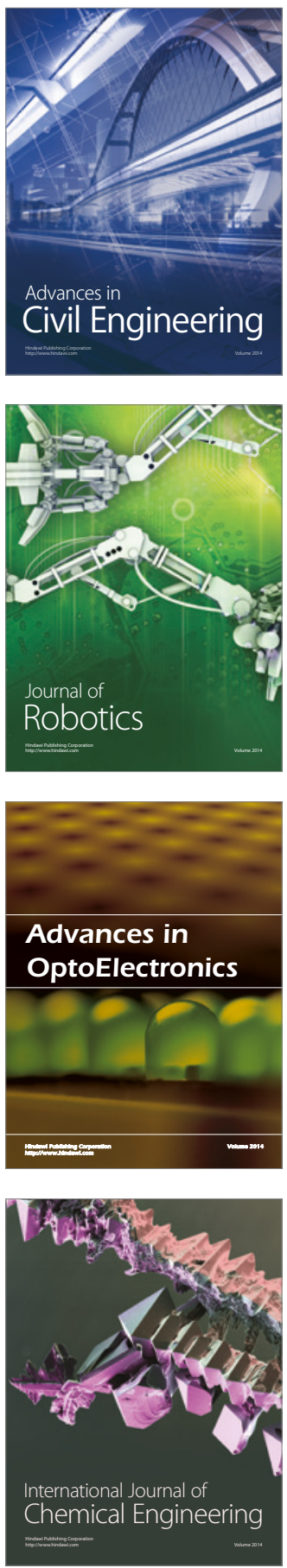

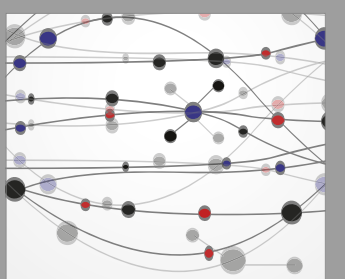

The Scientific World Journal

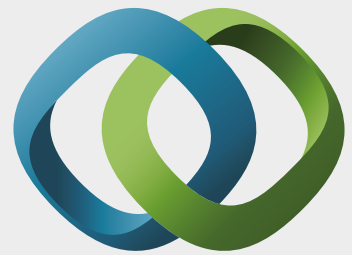

\section{Hindawi}

Submit your manuscripts at

https://www.hindawi.com
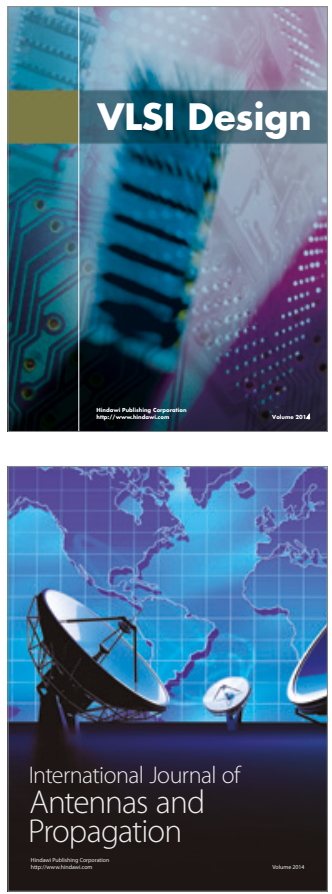

\section{Rotating}

Machinery
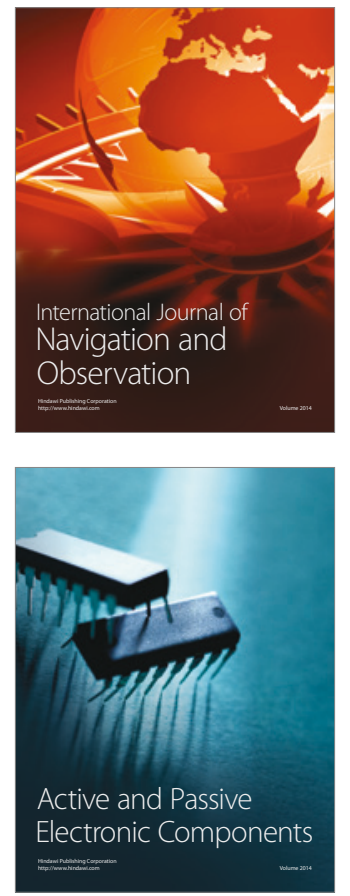
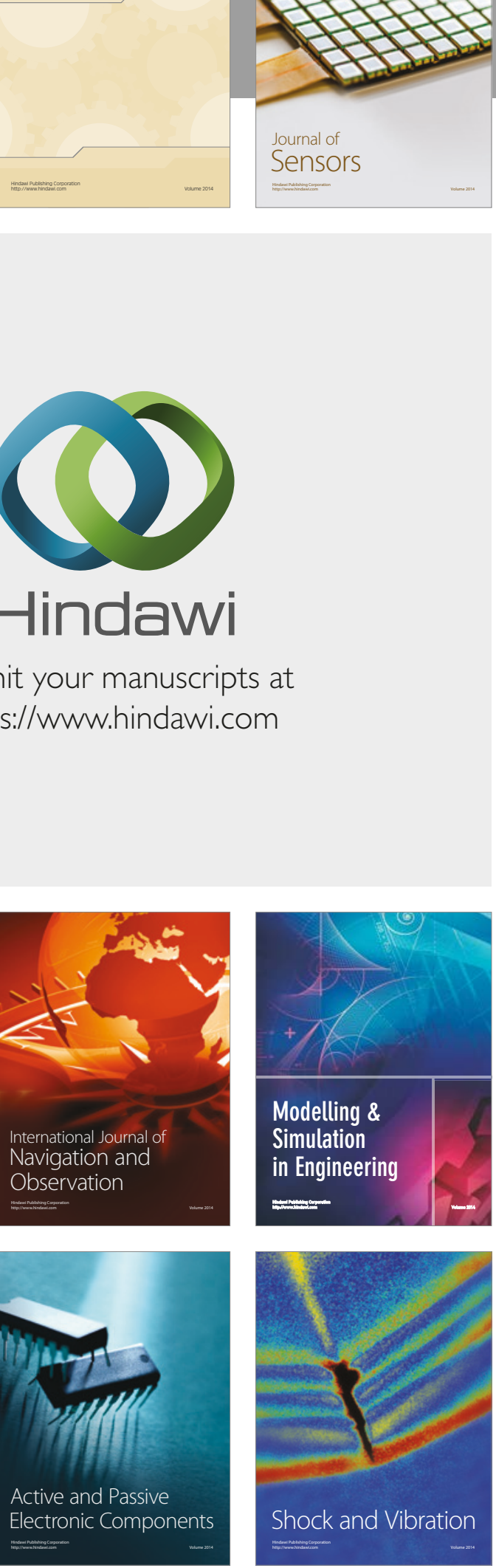
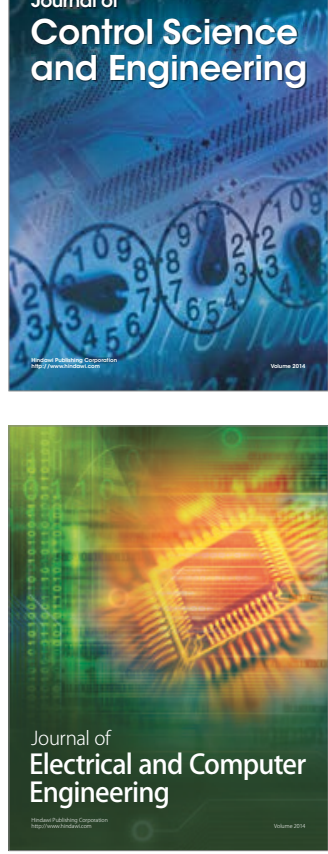

Distributed

Journal of

Control Science

and Engineering
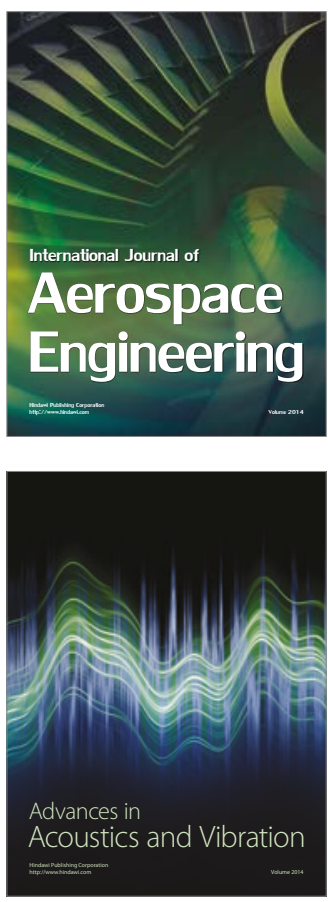

Sensor Networks 